\title{
Analysis of Middle Nubian Vessel-forming Technology Using Reflectance Transformation Imaging (RTI)
}

\author{
Aaron M. de Souza ${ }^{1 *}$, Martina Trognitz ${ }^{2}$ \\ ${ }^{1}$ Austrian Archaeological Institute, Austrian Academy of Sciences, Franz Klein-Gasse 1, 1190 Vienna, Austria \\ ${ }^{2}$ Austrian Centre for Digital Humanities and Cultural Heritage, Austrian Academy of Sciences, Sonnenfelsgasse 19, 1010 Vienna, Austria
}

\section{ARTICLE INFO}

\section{Article history:}

Received: $9^{\text {th }}$ September 2020

Accepted: $14^{\text {th }}$ April 2021

DOI: http://dx.doi.org/10.24916/iansa.2021.1.2

Key words:

Reflectance Transformation Imaging (RTI)

documentation

pottery technology

second millennium BCE

technological heritage

material culture

Kerma

Pan-Grave

C-Group

\begin{abstract}
$A B S T R A C T$
Reflectance Transformation Imaging (RTI) is a photographic technique used to generate digital surrogates of surfaces that can be viewed using virtual lighting coming from interactively set directions, enabling the close structural examination of objects under digital raking light.

In this study, RTI was applied to Middle Nubian pottery from sites near the Second Nile Cataract that were excavated by the Scandinavian Joint Expedition to Sudanese Nubia in the early 1960s. The ceramic traditions under investigation are currently known as C-Group, Pan-Grave and Kerma. An overarching aim of the project is to assess the possibility of understanding the relationships between these groups through detailed analyses of their material traditions. Based on the hypothesis that technological traditions may be related to cultural heritage, RTI is applied in this study to observe morphological traces of ceramic vessel forming processes.

Two technological groups were identified, one consistent with paddle-forming, and another consistent with hand-building on a mat-lined surface. These technological groups correspond very closely to cemetery distributions, which suggests that the different techniques may be specific to different potterymaking traditions. It is suggested that vessel forming-technology in the so-called C-Group tradition is distinct from that of the so-called Pan-Grave and Kerma traditions, and that the validity of the divisions between Nubian cultural groups should thus be further interrogated.
\end{abstract}

\section{Introduction}

According to the existing framework, the Nile Valley of Lower and Upper Nubia (Figure 1) was populated by three so-called Middle Nubian Cultures - the C-Group, Kerma, and Pan-Grave cultures - during a period spanning c. 1850-1500 BCE (Figure 2). Each of the three groups was defined typologically, based on distinct material culture traditions and patterns of distribution following a now outdated culture-historical approach. The C-Group was thought to be confined primarily to Lower Nubia (Bietak, 1968; Säve-Söderbergh, 1989), the Kerma tradition to Upper Nubia (Edwards, 2004, pp.65-84), while the Pan-Grave tradition comprised mobile or partially mobile groups spread across a vast region from Middle Egypt up to the Fourth Nile Cataract and the surrounding desert regions (Bietak, 1966; Säve-Söderbergh, 1989, pp.15-19; de Souza, 2019, pp.140-143). For much of the $20^{\text {th }}$ century, these three archaeological cultures were viewed as bounded and distinct

*Corresponding author. E-mail: aaron.desouza@oeaw.ac.at entities, but recent research has demonstrated that these divisions can no longer be supported. It is now understood that the Nubian cultural landscape was highly complex and interconnected (Edwards, 2004, pp.10-23; Raue, 2019, pp.293-333), but the outdated divisions persist in scholarly discourse. In the absence of any alternative descriptive system, the labels C-Group, Pan-Grave, and Kerma will be used in this paper for reasons of clarity, albeit with the recognition that those labels need to be urgently revised.

In order to investigate these interconnections, the current analysis uses the concept of chaîne opératoire (Gosselain, 2012, pp.244-246; Roux, 2016; D’Ercole et al., 2017, p.554; Gosselain, 2018) as a means for understanding the series of choices made by ancient Nubian potters when making these vessels. According to Gosselain (2012, p.246), the concept is also an analytical tool for documenting and interpreting those technological choices in a systematic way. This study applies Reflectance Transformation Imaging (RTI) to Middle Nubian ceramics in order to identify and analyse physical traces of the vessel-forming process that might otherwise be invisible to the unaided eye or difficult to capture using 


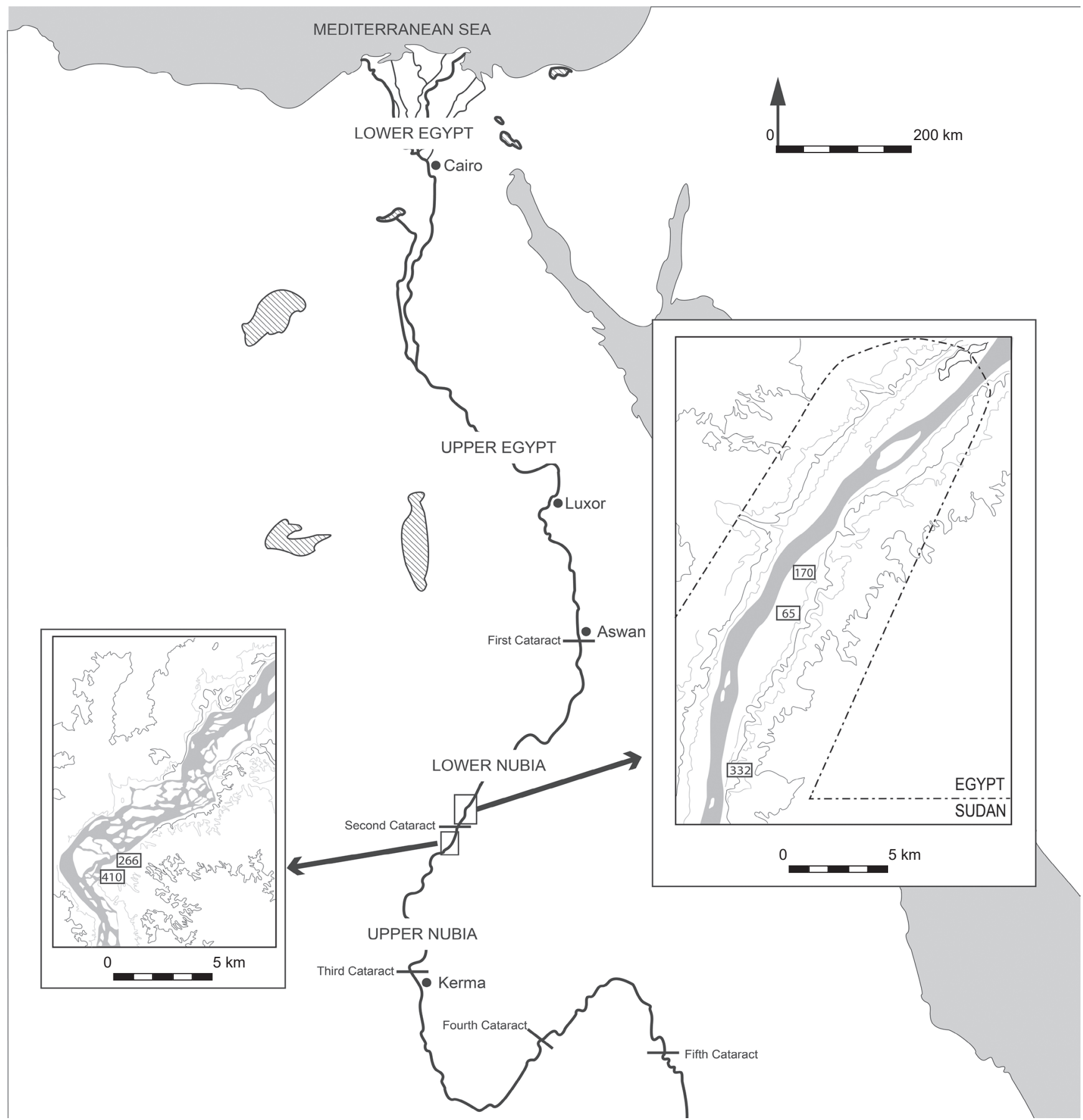

Figure 1. Map of Egypt and Nubia showing the locations of the SJE concession and the sites from which samples were taken. Map by A. de Souza.

standard photographic processes (see chapter 4). It will be shown that careful observation of the surface features revealed by the RTI process can assist in identifying similarities or differences in pottery-making technologies that may in turn be linked to cultural heritage and traditions.

\section{Research objective}

The goal of the analysis was to test hypotheses regarding ceramic vessel-forming technologies among the Middle
Nubian cultures. It has previously been proposed that Nubian pottery was formed using either the coiling or slab-building method (Arnold, 1993, pp.33-36), or by using a percussive process such as paddle forming (Arnold, 1993, pp.17-20). Both of these methods have been cited as primary forming processes (i.e., the processes used to create the overall vessel shape), and it is likely that both slab building and paddle forming (see chapter 6.1) were employed for different types of vessels and perhaps even in combination (Nordström, 1972, pp.47-48; Williams, 1983, pp.29-36). RTI was employed on a group of Middle Nubian vessels selected from the 
Figure 2. Comparative timeline of ancient Egypt and Nubia.

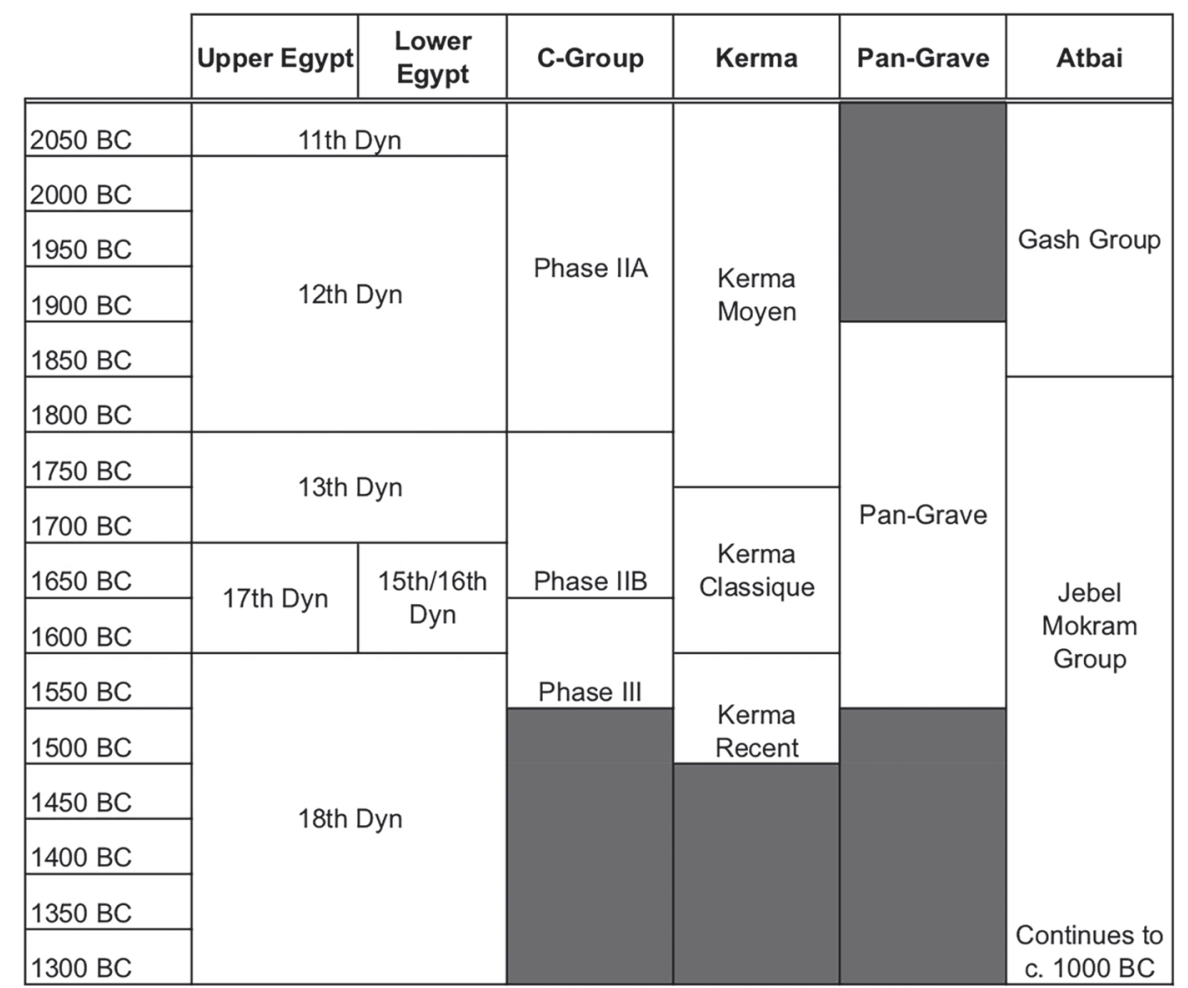

Scandinavian Joint Expedition (SJE) collection in order to identify physical traces of vessel-forming technologies that might otherwise be invisible to the unaided eye. These new insights might also revise understandings of Middle Nubian ceramic technologies and, by extension, critically reconsider the existing Nubian cultural divisions.

\section{Samples and sites}

The samples for the analysis were all selected from objects collected by the Scandinavian Joint Expedition to Sudanese Nubia (the "SJE"), the bulk of which are now housed at the Museum Gustavianum, Uppsala University, Sweden (SäveSöderbergh, 1970, pp.13-18). All objects were exported from Sudan in accordance with the agreed division of finds, and full permission to document the objects using RTI was granted by the curatorial staff of the Museum Gustavianum. A total of 25 objects drawn from five cemetery sites were documented using RTI. The 15 objects that yielded meaningful information are summarised in Table 1 . The remaining 10 objects that produced inconclusive results are listed in Table 2. As the aim of the analysis is to look for technological variations between pottery-making traditions according to their current definitions, the sample selection was limited to objects that could be attributed to one of the existing cultural divisions with relative security. Attributions were based on characteristics such as shape, ware and overall style, as well as considerations of the archaeological contexts in which the objects were found. Regarding chronology, at present there is no absolute chronology for the Middle
Nubian traditions and, as such, only a relative sequence can be given.

All of the samples are undecorated black-top wares with a range of surface treatments including coated and uncoated, burnished and unburnished. In order to capture as much of the vessel surface as possible, complete or intact objects were prioritised for selection. In cases where intact objects were not available, the largest possible sherds that preserved all or most of the vessel profile were selected for analysis.

Ten samples came from SJE Site 65, all of which could be attributed to the so-called C-Group tradition based on morphology, ware, and the character of their respective contexts. SJE Site 65 as a whole may also be attributed to the C-Group tradition and is broadly contemporary with the late Middle Kingdom and Second Intermediate Period on the Egyptian timeline (Säve-Söderbergh, 1989, pp.174-180). All of the samples are black-topped bowls with red-coated and burnished exteriors (Figures 5a, 5c, 5e and 6a, 6c, 6e).

Five samples were taken from SJE Site 170, which has mostly been attributed to the so-called Pan-Grave cultural horizon (de Souza, 2019, pp.150-153) with some evidence for activity related to the Kerma tradition. The site is roughly contemporary with the late Second Intermediate Period in Egypt (Säve-Söderbergh, 1989, pp.192-199). Of the five samples from Site 170, three could be attributed to the PanGrave ceramic tradition based on their overall style and morphology (Table 1; Figures 7c, 7e, 8a). The fourth sample, 170/39:3 (Figure 9), is a small shallow bowl with a matimpressed exterior that strongly suggests a Kerma attribution based on parallels with the same surface treatment from sites in Upper Nubia (for parallels, see: Ruffieux, 2012, fig. 28; 
Table 1. List of RTI samples that yielded meaningful information.

\begin{tabular}{llll}
\hline Object No. & Tradition & Preservation & Surface features noted in RTI \\
\hline 65/0:9 & C-Group & Intact & Parallel ripples from base to rim. \\
65/2:1 & C-Group & Sherd & Areas of flat zones, some elongated narrow depressions. \\
65/62A:1 & C-Group & Sherd & Large flat areas to exterior. \\
65/63:1 & C-Group & Sherd & Large flat areas to exterior. \\
65/107:2 & C-Group & Sherd & Flat marks toward base, some parallel grooves on max diameter. \\
65/239:4 & C-Group & Complete & Flat areas to exterior. \\
170/2:1 & Pan-Grave & Complete & Small circular dimples toward base; vertical burnishing and scrape marks to upper body. \\
170/30:1 & Pan-Grave & Intact & Clusters of small dimples toward base. \\
170/31:2 & Pan-Grave & Intact & Clusters of small dimples toward base. \\
170/38:2 & Pan-Grave? & Sherd & Parallel ripples from base to rim. \\
170/39:3 & Kerma? & Intact & Mat impressed; covered with irregular rounded dimples. \\
266/B.1.2 & Kerma & Intact & Mat impressed; entire exterior surface covered in rows of circular dimples. \\
332/33:2 & Pan-Grave & Intact & Clusters of dimples toward base. \\
410/7:4 & Kerma & Sherd & Mat impressed; covered with impressions of herringbone weave. \\
410/21:2 & Pan-Grave & Sherd & Patches of small dimples and one large flat area. \\
\hline
\end{tabular}

Table 2. List of RTI samples for which the results were inconclusive.

\begin{tabular}{clll}
\hline Object No. & Tradition & Preservation & Reason for exclusion \\
\hline 65/21:1(5) & C-Group & Sherd & RTI taken of interior surface only. Comb scraped surface. \\
65/64:4(3) & C-Group & Sherd & Sherd too small, no traces of forming processes observed. \\
65/246:1 & C-Group? & Sherds & No traces of forming processes observed. \\
65/311:2 & C-Group & Sherd & Sherd too small, no traces of forming processes observed. \\
170/05:1 & Pan-Grave? & Sherd & Sherd too small, no traces of forming processes observed. \\
170/37:2 & Kerma & Intact & Kerma beaker; surface highly polished, no traces of forming processes observed. \\
170/37:3 & Kerma & Intact & Kerma beaker; burnishing has erased traces of forming processes. \\
170/46:1 & Pan-Grave? & Intact & No traces of forming processes observed. \\
410/20:1 & Kerma & Incomplete & Kerma beaker; burnishing has erased traces of forming processes. \\
410/23:1 & Kerma & Intact & Kerma beaker; burnishing has erased traces of forming processes. \\
\hline
\end{tabular}

Rose, 2012, pp.18-21, fig. 4-5; Budka, 2017, fig. 67). The attribution of the fifth sample, 170/38:2, is uncertain, but it has been tentatively assigned to the Pan-Grave ceramic tradition by association and by its macroscopic characteristics (Figure 8c). Four additional samples from this site yielded inconclusive results (Table 2).

One vessel comes from grave $266 \mathrm{~B}$, which is an isolated burial in the vicinity of a larger cemetery that was attributed by the excavators to the C-Group (Säve-Söderbergh, 1989, pp.239-240). The vessel is a large globular jar with a matimpressed exterior surface that is consistent with examples known from the Kerma tradition.

A small black-topped bowl (332/33:2), came from SJE Site 332, which was identified by the excavators as a "Middle Nubian (C-Group?) and Late Nubian cemetery", with some earlier elements (Säve-Söderbergh, 1989, p.246). The character of the context is undetermined, but the bowl itself could be attributed to the Pan-Grave tradition based on its overall morphology.
Four samples were drawn from SJE Site 410, one of the southernmost sites in the SJE concession located in the vicinity of the second Nile Cataract. This site was described by the excavators as a mixed Pan-Grave and Kerma cemetery and most graves were identified by loose stone rings at the surface (Säve-Söderbergh, 1989, pp.251-254, pl. 158-159). One sherd has an obviously mat-impressed surface consistent with examples known from the Kerma tradition (Figure 4). Another bowl with a defined black-top could be attributed to the Pan-Grave tradition on stylistic grounds (Figure 8a). In addition, two Classic Kerma beakers from this site (SäveSöderbergh, 1989, pl. 23) were documented using RTI, but their highly polished surfaces produced unusable results (Table 2).

Regarding chronology, all of the graves, and in particular those from SJE Site 65, were at least partially disturbed and easily dateable objects were almost entirely absent. Based on the pottery forms, it was possible to devise a broad relative sequence. The vessels attributed to the C-Group pottery 
tradition are all relatively shallow with tapered bases that are characteristic of a relatively early date, most likely Bietak's Phase IB or IIA (Bietak, 1968, pp.96-105, Taf. 8; SäveSöderbergh, 1989, pp.7-9), which more or less corresponds to the $12^{\text {th }}$ Dynasty in Egypt, c. $2000-1800$ BCE. The overall style of the vessels attributed to the Pan-Grave and Kerma traditions as well as their find contexts suggest a slightly later date in the Second Intermediate Period in Egypt, c. 1650-1550 BCE. For samples attributed to the Pan-Grave tradition, characteristics such as defined and applied blacktops point to a date during the later phases for that tradition (de Souza, 2019, pp.35-37, pp.119-122). For the matimpressed wares assigned to the Kerma tradition from SJE Sites 170 and 410, well-dated parallels and the presence of well-known beaker forms point towards a date in the Classic Kerma period (c. 1700-1500 BCE). Overall, it would appear that the C-Group samples from SJE Site 65 are earlier than the Pan-Grave and Kerma samples, which are more or less contemporary with one another.

\section{The RTI method}

Reflectance Transformation Imaging (RTI) is a photographic technique used to generate digital surrogates of surfaces that can be viewed with light coming from an interactively set direction, enabling the examination of objects under digital raking light. The method involves taking multiple photographs (the "image stack") of an object with a camera positioned perpendicularly to it, with a moving light source, i.e., the object and camera remain stationary, but the light source is moved around the object and comes from a different angle in each picture. Digital relighting is enabled by the use of Polynomial Texture Maps (PTM), a digital image format that does not store a fixed colour value for each pixel, but instead uses a reflectance function to calculate the luminosity of the surface, which influences how a surface is visually perceived: bright, dark, reflective or dim. Simply put, the colour is computed depending on the view settings (e.g. incident light angle) and the surface geometry, i.e., the surface normals, of the captured object (Malzbender et al., 2001, p.521; Trognitz, 2016). Surface normals represent points on a three-dimensional object where a normal can be determined along which, according to the law of reflection, extant light is reflected in the same angle as incident light
(Figure 3). The reflectance function allows for an accurate representation of the three-dimensional surface's shape in a two-dimensional PTM.

In order to calculate the PTM from the image stack, the position of the light source in each image must be known. This can be achieved in one of two ways: by using a domeshaped device with fixed mounted lights that surrounds the object (Malzbender et al., 2001, pp.520-521) or by using a hand-held light source for which the origin can be calculated by using reflective spheres placed in the image frame (Mudge et al., 2006). The latter method, known as Highlight RTI (H-RTI), is detailed by CHI (Web CHI b) and Historic England (2018, pp.7-23) and was employed for the present analysis. With H-RTI, a virtual "dome" of light around the object is created by manually positioning the light source along imaginary arcs. The current recommended H-RTI workflow, software for building and viewing an RTI file, and further related methods were developed by Cultural Heritage Imaging (CHI), who openly and freely provide their materials and also offer in-depth, hands-on training classes.

The inherently curved surfaces of the vessels in this analysis required certain considerations in capturing the images. In order to compensate for the curvature, the camera was set to capture an increased depth-of-field using a wide aperture (F18-22) and prolonged exposure time (up to 2 seconds) to ensure that the entirety of the vessel surface was in focus. The prolonged exposure time in turn dictated that a continuous light source was required, in this case, a hand-held LED torch, rather than a conventional flash. A string attached to the light source assisted in maintaining a consistent distance to the object. The torch was moved along a series of twelve imaginary arcs, each of which comprised four individual images. With three additional images in which the light source was held further away from the object, each object was thus captured with a total of 51 photographs. The last three images were optional and used only if additional filling light was required to brighten the final image.

The captured image stacks were computed into an RTI file with the RTIBuilder software developed by Cultural Heritage Imaging (CHI) (Web CHI a). The finished RTI files can only be viewed with specialised software, in this case, the RTIViewer developed by CHI (Web CHI d) was used. RTIViewer Version 1.1 offers a range of rendering modes, each with further sub modes and settings (Malzbender et al., 2000; Malzbender et al., 2001, pp.525-526; Palma et al.,

Figure 3. On a three-dimensional surface the surface normals (red dashed) point into different directions. The incident light (yellow) is reflected (green) along the surface normal. A PTM (Polynomial Texture Map) stores the surface normals and the incident light angle and can visually provide an accurate representation of the threedimensional surface in a two-dimensional file. (CC-BY 4.0 M. Trognitz)
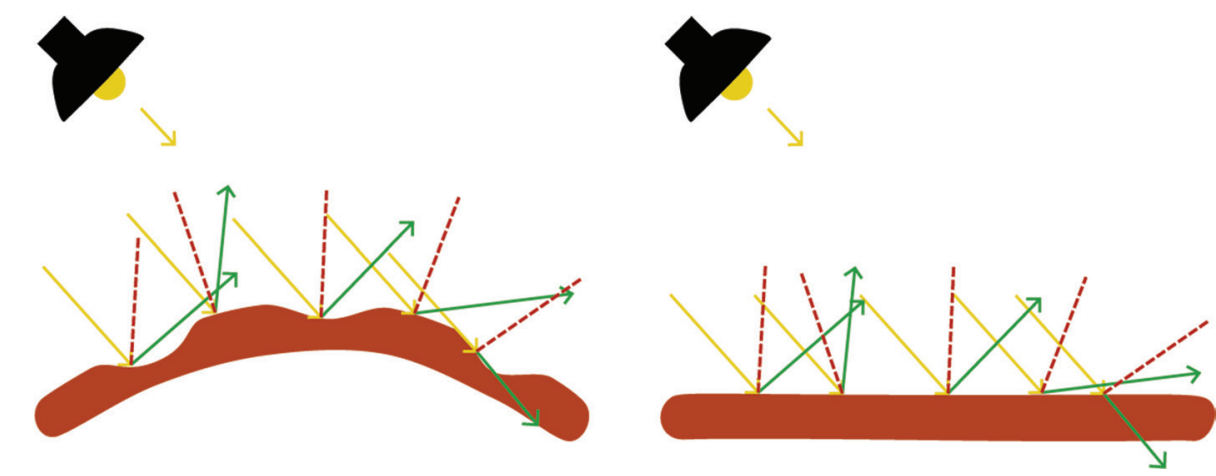


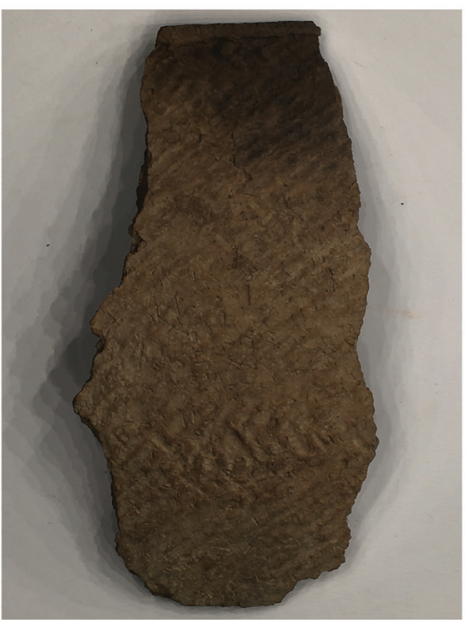

a) Default

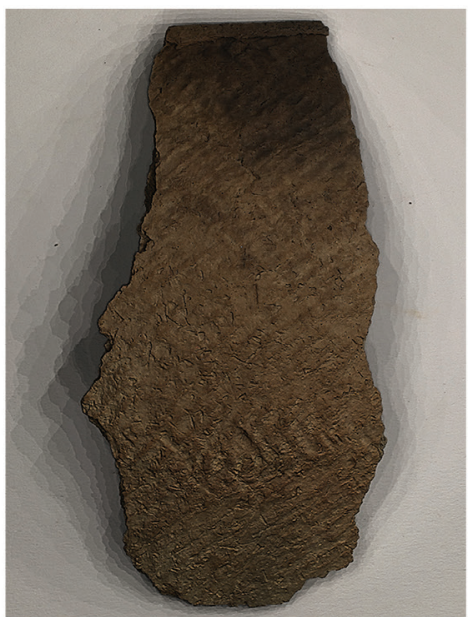

d) Luminance Unsharp Masking

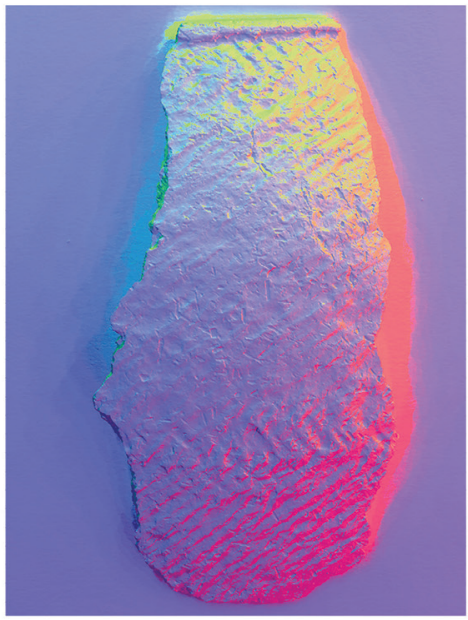

g) Normals Visualisation

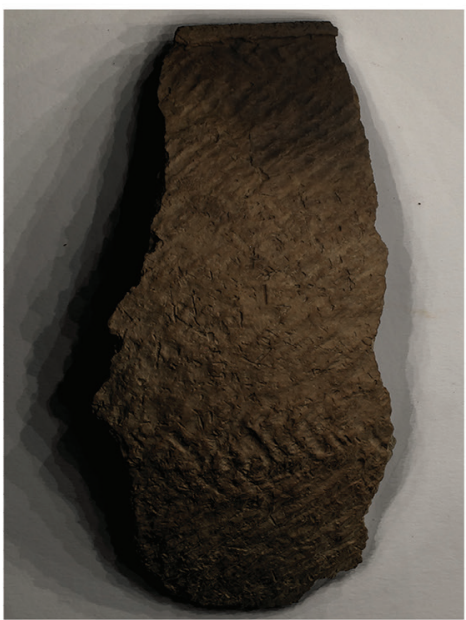

b) Diffuse Gain

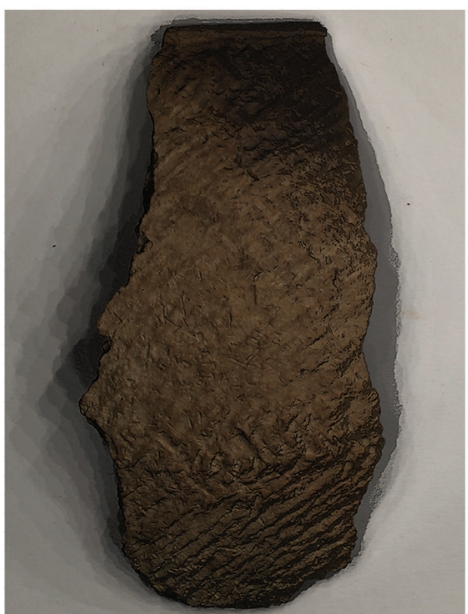

e) Normals Unsharp Masking

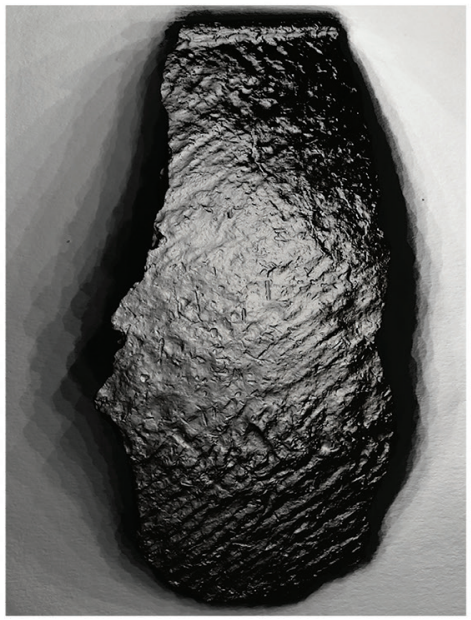

h) Specular Enhancement

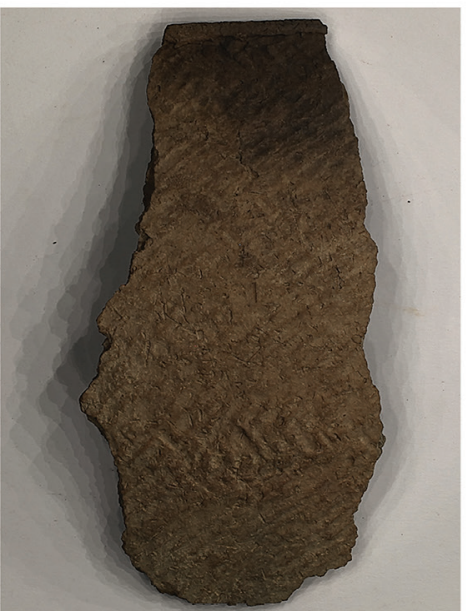

c) Image Unsharp Masking

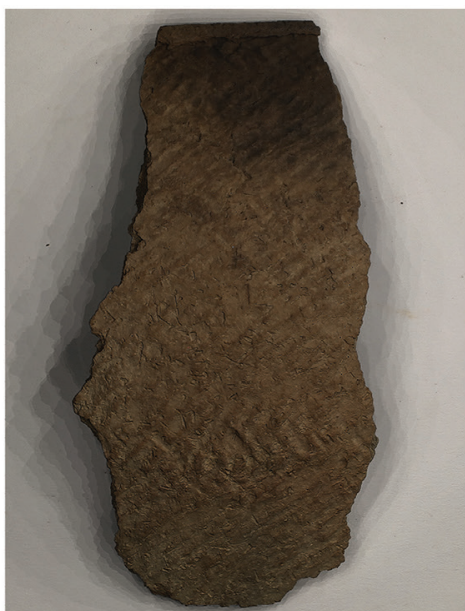

f) Coefficient Unsharp Masking

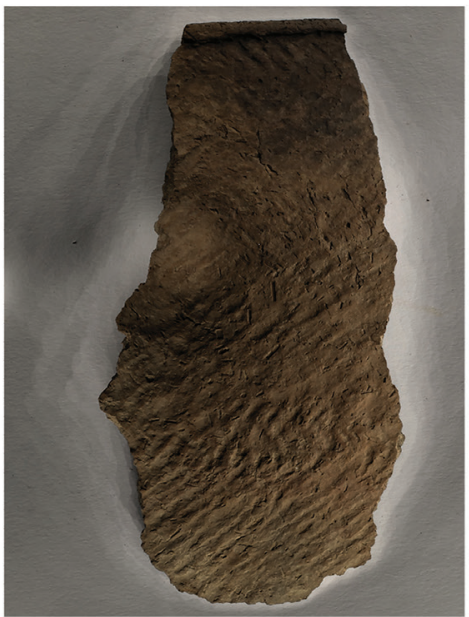

i) Static Multi Light

Figure 4. Sample SJE 410/7:4 rendered using different visualisation modes under the same lighting conditions. Each mode enhances the visual perception of shape and surface detail in different ways.

2010, pp.6:5-6:7; CHI, 2013, pp.13-23; Schroer, 2014). These rendering algorithms help in enhancing the visual perception of shape and surface detail by, for example, changing material properties of objects or enhancing shape cues provided by shading (Malzbender et al., 2000).
Figure 4 serves as an example of the effects that different rendering algorithms have on the perception of the object's shape and surface textures for sample SJE 410/7:4. Of all of the available viewing modes, specular enhancement proved most useful for the current analysis in that it best 
aided in the visualisation of often very subtle manufacturing traces preserved on the surface of the vessels (Figure 4h; Malzbender et al., 2000; 2001, pp.525). This viewing mode also enables the image to be desaturated and hence brings focus to the structure of the object without the distraction of colour.

For archaeological purposes, the RTI process is a versatile, mobile, and relatively low-cost method of documenting objects for detailed digital analysis both in the field and in a museum or laboratory setting. The mobile equipment enables working in a variety of indoor and outdoor settings, including remote areas and even underwater settings (Historic England, 2018, pp.52-54). Virtually any material can be captured (Earl et al., 2010; Earl et al., 2011), with object sizes ranging from the microscopic (Historic England, 2018, pp.45-48) up to larger objects or even to complete sites (Historic England, 2018, pp.49-51). The samples of the RTI Systems for Ancient Documentary Artefacts project (AHRC RTISAD) include materials such as ceramic, wood, metal, stone or bone (Earl et al., 2011, pp.151) with surface finishes ranging from matte to shiny. The different rendering methods provide extended tools for analysis beyond what is visible with the unaided eye or difficult to capture using traditional photographic methods, while still clearly representing 3D shape characteristics. Finally, RTI-files provide a perfectly lit and location-independent means for the study of an object's surface, thus providing "access to colour and texture in a way hitherto largely restricted to those in direct contact with the material culture" (Earl et al., 2010, pp.2049). For its application to Nubian-style pottery specifically, RTI has also been used to analyse pottery that combines Nubian and Egyptian technologies at the sites of Wadi el-Hudi (Brand, 2018, pp.36-37, fig. 9-10) and at Tell Edfu (de Souza, 2020, p.316, fig. 6).

Like every documentation method, besides its advantages, RTI also has disadvantages that may limit its applicability to archaeology, largely dictated by the shape, size, or location of the object to be documented.

Ideally, the surface being photographed should be as flat as possible. Curved objects, for example, the interior of a vessel, can be difficult or impossible to photograph using RTI due to extensive self-shadowing. Objects with a less pronounced curvature might still be viable for RTI if the camera's depth of field can be adjusted accordingly, as was the case for this analysis. Curved objects or objects with multiple sides can be documented, but photographing the entire object requires multiple image stacks taken from different angles. 3D scanning may be a more viable option for these kinds of objects.

Although the process is portable, sufficient space around the object being documented is needed. The object should be positioned in the centre of the real or virtual dome, which itself should have a radius of at least two times the diameter of the object. Therefore, particularly large objects require an accordingly large surrounding space. The viability of RTI can also be limited in confined spaces such as a tomb, a cave, or a museum storeroom. The equipment itself can also pose challenges, for example, the legs of a tripod, which can cast shadows over the object when using the H-RTI method.

Ambient light and especially daylight must also be considered, as the artificial light source should ideally be the only light source in the captured images. However, it is possible to conduct RTI outdoors in a shaded location provided that the light conditions are consistent and the exposure time and aperture are adjusted to reduce natural ambient light in the digital images.

\section{Results}

The results relating to the 15 samples that yielded meaningful information are summarised in Table 1. The RTI files and data are accessible via ARCHE (A Resource Centre for the HumanitiEs): http://hdl.handle.net/21.11115/0000-000DFEA5-B.

All but one of the samples from Site 65 displayed large flattened facets on their exterior surfaces, especially towards the base (Figures 5 and 6). Sample 65/2:1 (Figures 5a-b) also displays elongated depressions. Sample 65/0:9 does not have any obvious flattened facets at the base but does display parallel ripples running from the base to the rim (Figures 5e-f).

Of the five samples from Site 170, three specimens (Table 1; Figures 7c/e, 8a) each display clusters of small rounded dimples towards the base that have been partially diminished by the burnishing process (Figure $7 d / f, 8 b$ ). The dimples are approximately $5-7 \mathrm{~mm}$ in diameter. The mat-impressed surface of the shallow bowl assigned to the Kerma ceramic tradition, (170/39:3, Figure 9), can be easily discerned with the unaided eye, and while RTI significantly enhances the visualisation of the surface texture, the weave pattern of the mat could not be easily discerned. It appears to have been tightly woven with small rounded loops, similar to the three aforementioned samples. The cultural attribution of a fourth sample from the site, 170/38:2, is uncertain, but it has been tentatively attributed to the Pan-Grave ceramic tradition based on its context (Figure 8c). This sherd does not display the clusters of dimples but rather shows parallel ripples running vertically between the base and the nowmissing rim (Figure 8d).

The mat-impressed surface of the large jar 266/B.1.2 (Figure 10) was visible with the unaided eye, but enhancement through the RTI process revealed a weave pattern comprising parallel rows of small circular impressions. The size of the impressions (approx. $5 \mathrm{~mm}$ diameter) is consistent with those observed on the samples from SJE Site 170.

Sample 332/33:2 is a small bowl attributed to the Pan-Grave ceramic tradition based on its overall morphology (Figure 7ab). This bowl displayed the same clusters of small circular dimples as those observed the examples from Site 170 .

Clusters of larger dimples were observed on the base of SJE 410/21:2, a small Pan-Grave style bowl (Figure 8e-f).

No informative surface details were observed on the 10 samples that have been excluded in ensuing discussions 
a

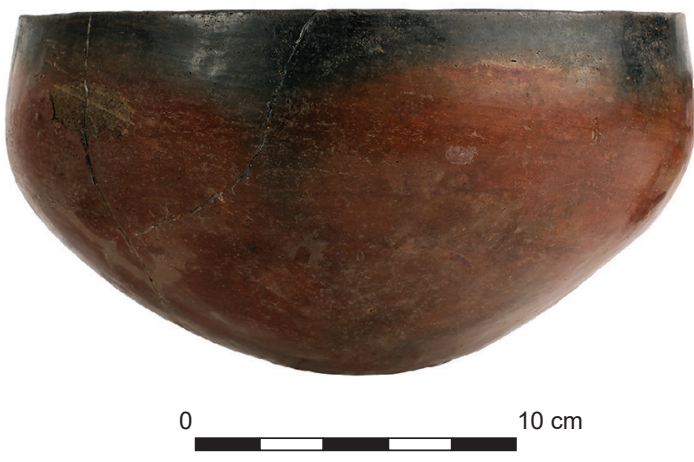

$c$

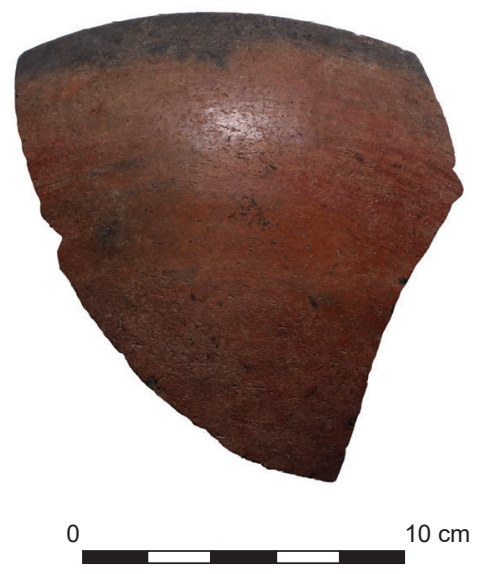

e

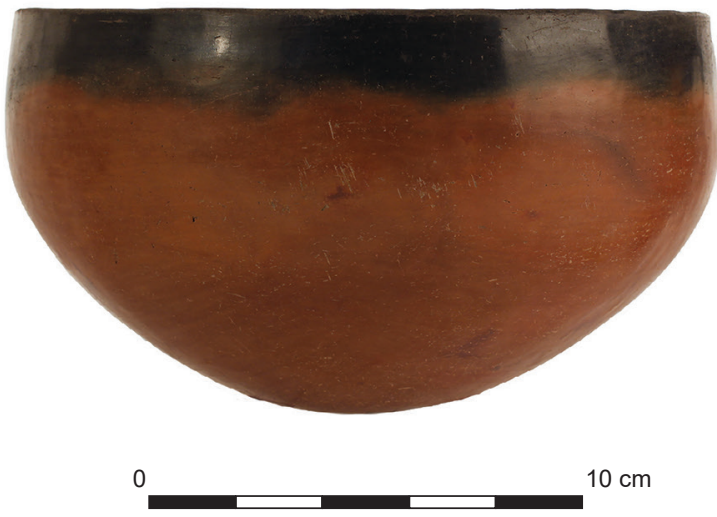

b

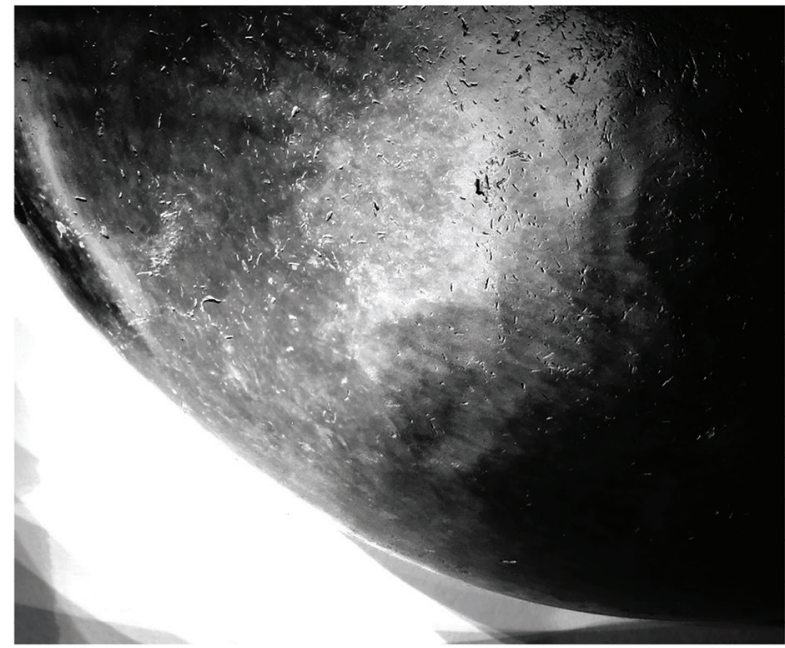

d

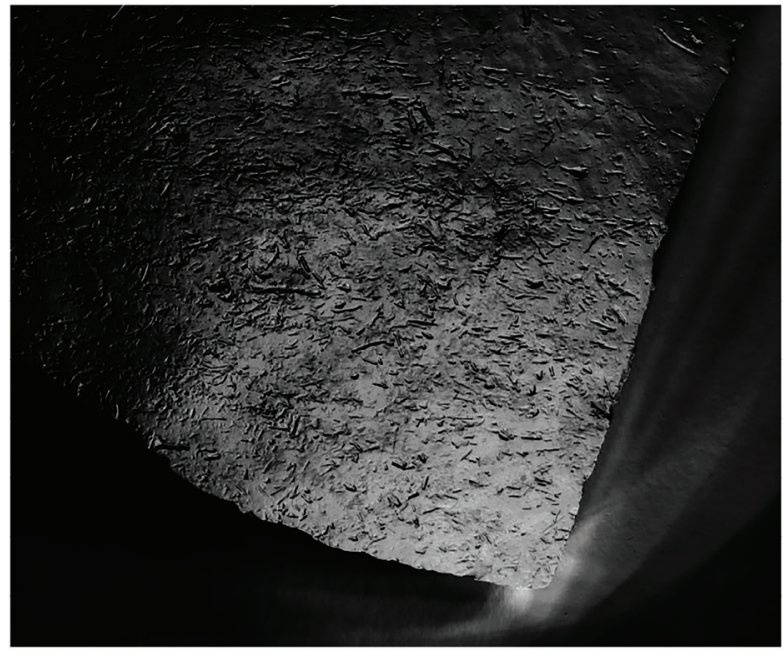

f

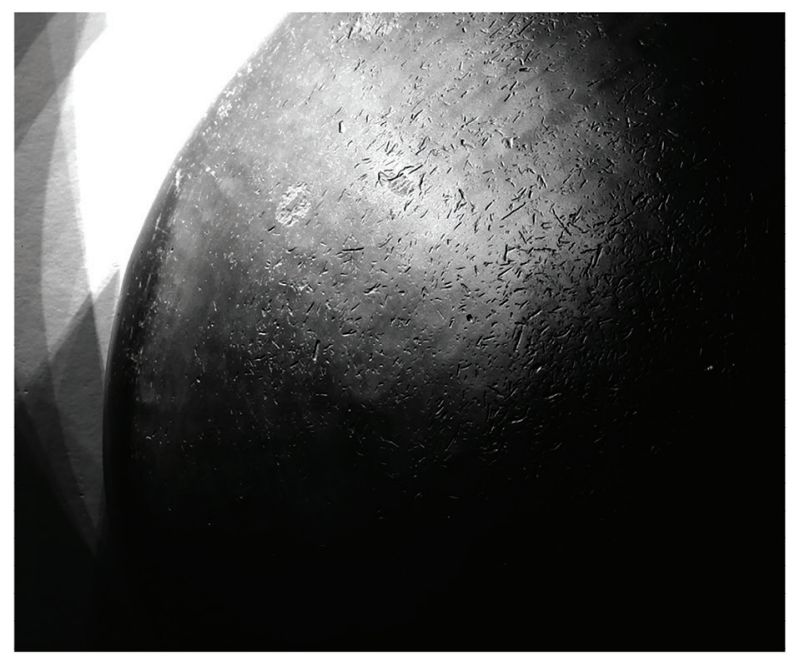

Figure 5. Samples from SJE Site 65: (a) 65/2:1 photograph (b) 65/2:1 RTI in specular enhancement mode; (c) 65/107:2 photograph (d) 65/107:2 RTI in specular enhancement mode; (e) 65/0:9 photograph (f) 65/0:9 RTI in specular enhancement mode. 


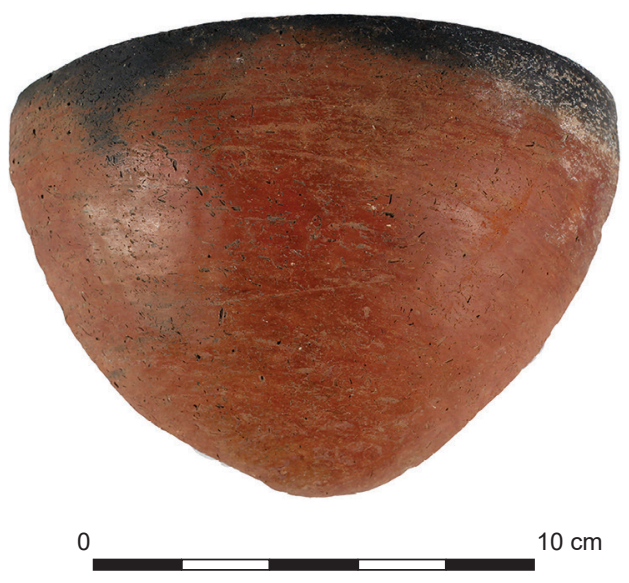

$\mathrm{C}$
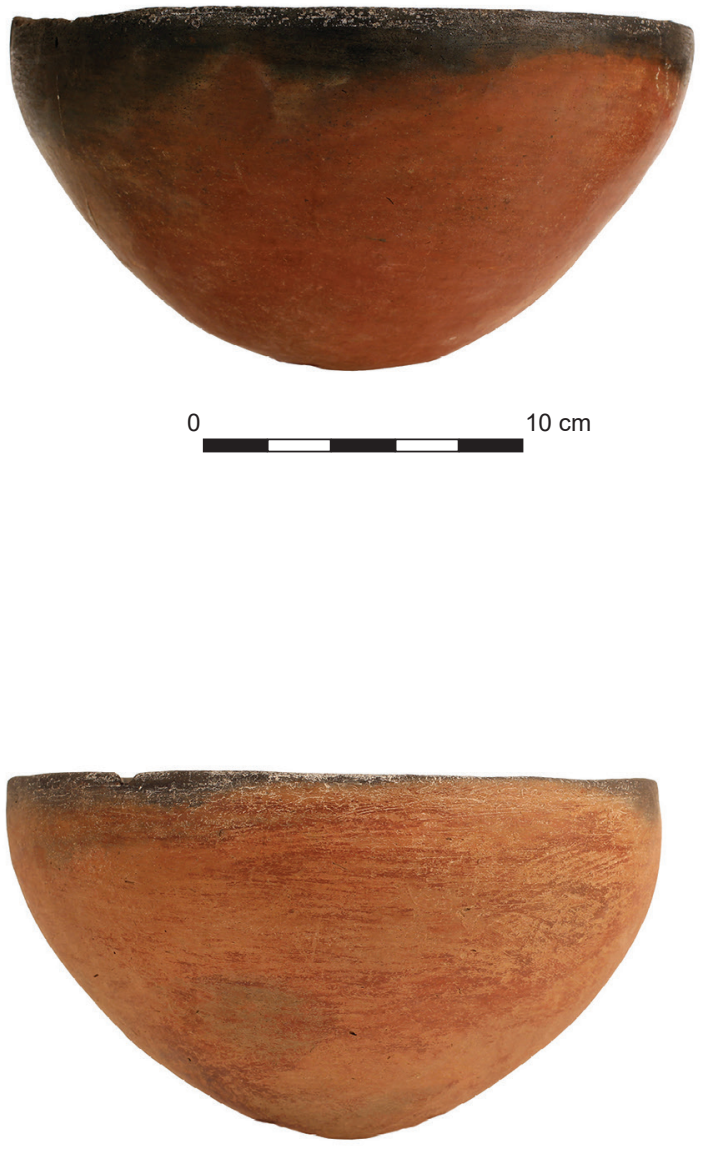

0 $10 \mathrm{~cm}$ b

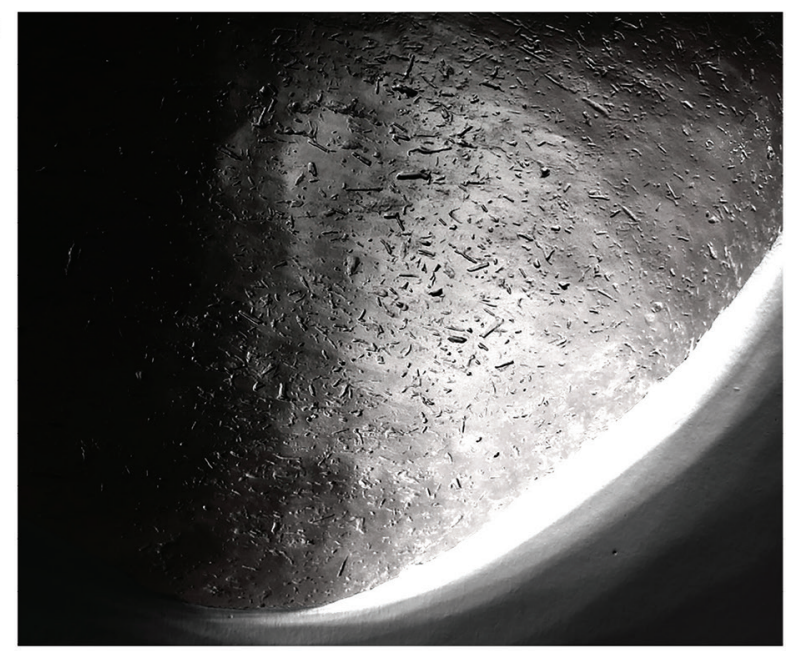

d

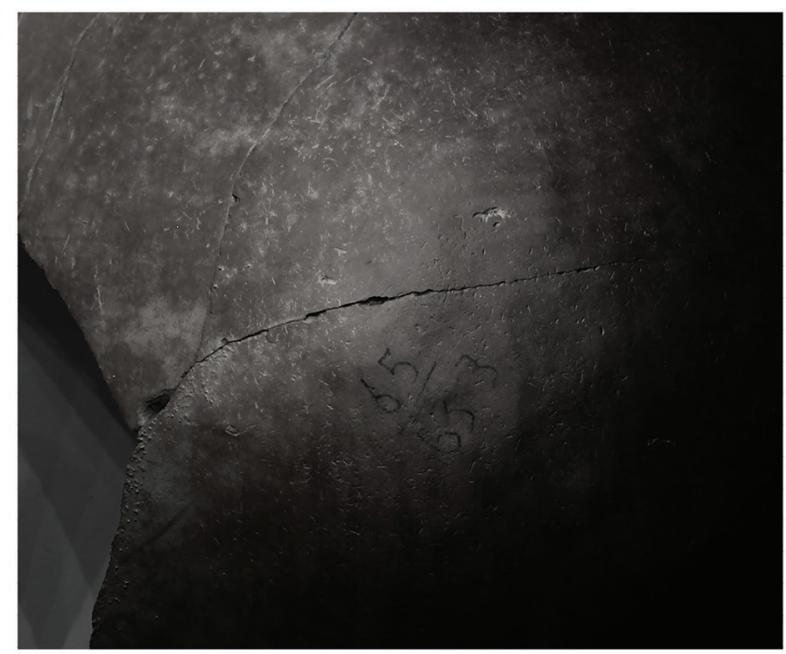

f

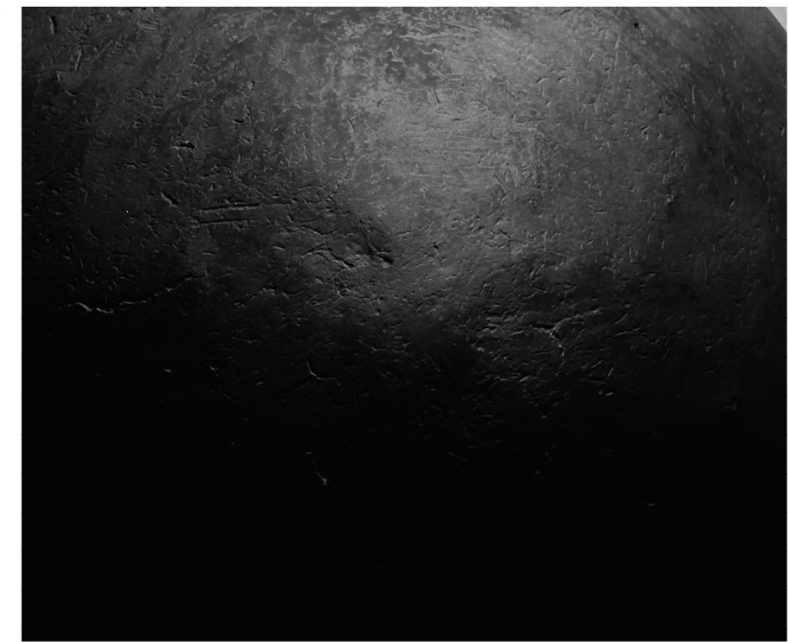

Figure 6. Samples from SJE Site 65: (a) 65/62A:1 photograph (b) 65/62:1 RTI in specular enhancement mode; (c) 65/63:1 photograph (d) 65/63:1 RTI in specular enhancement mode; (e) 65/239:4 photograph (f) 65/239:4 RTI in specular enhancement mode. 


\section{b}

a
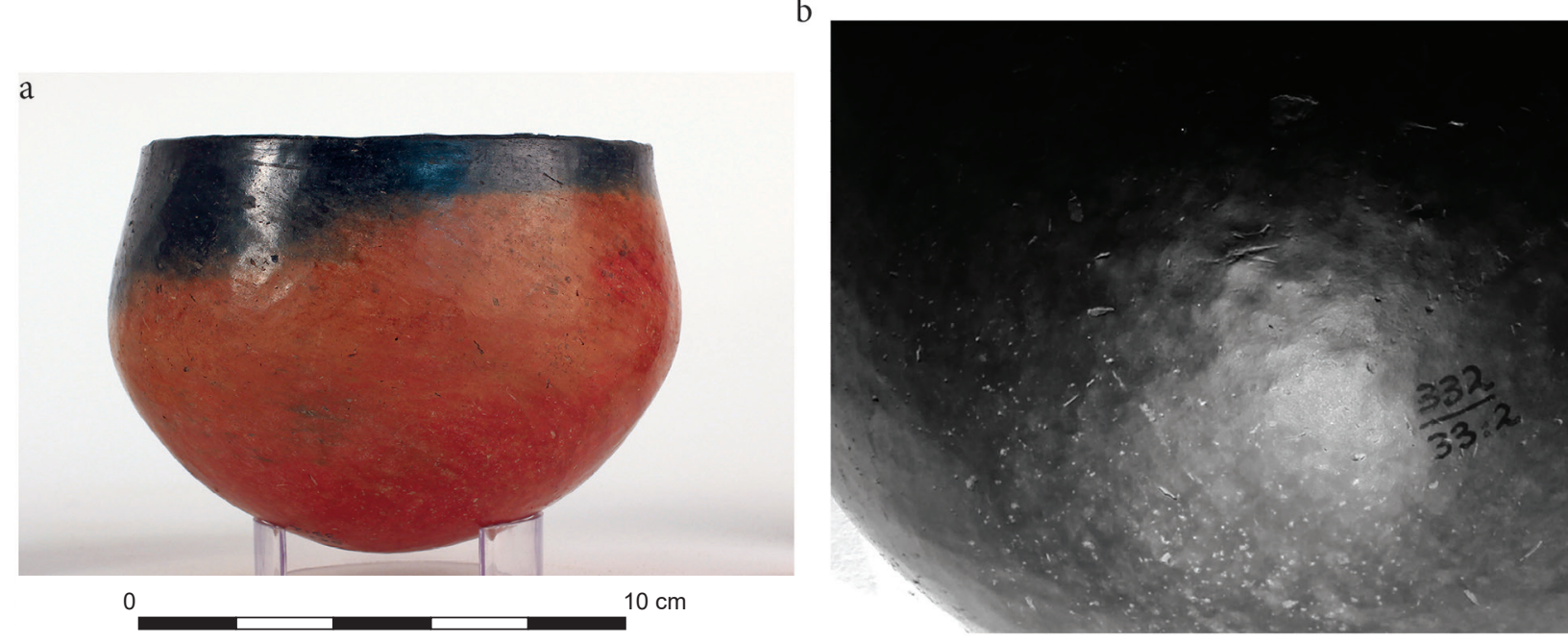

C

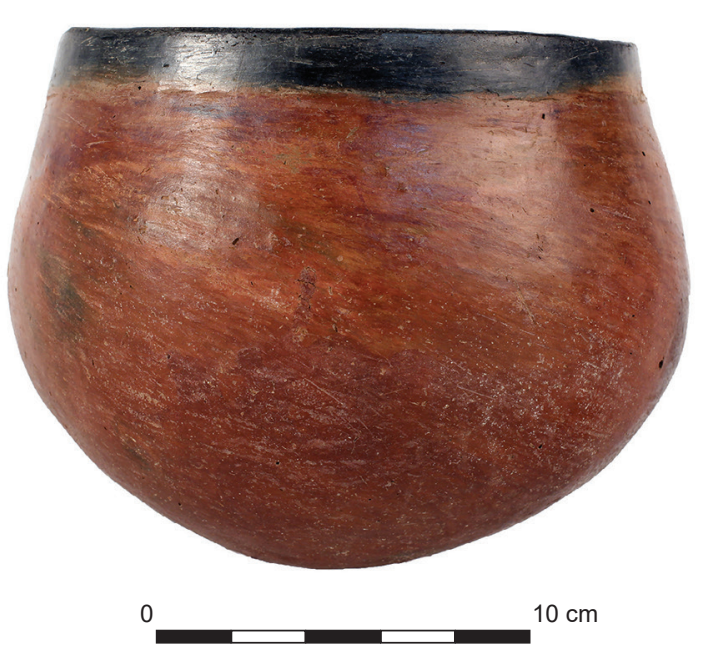

d

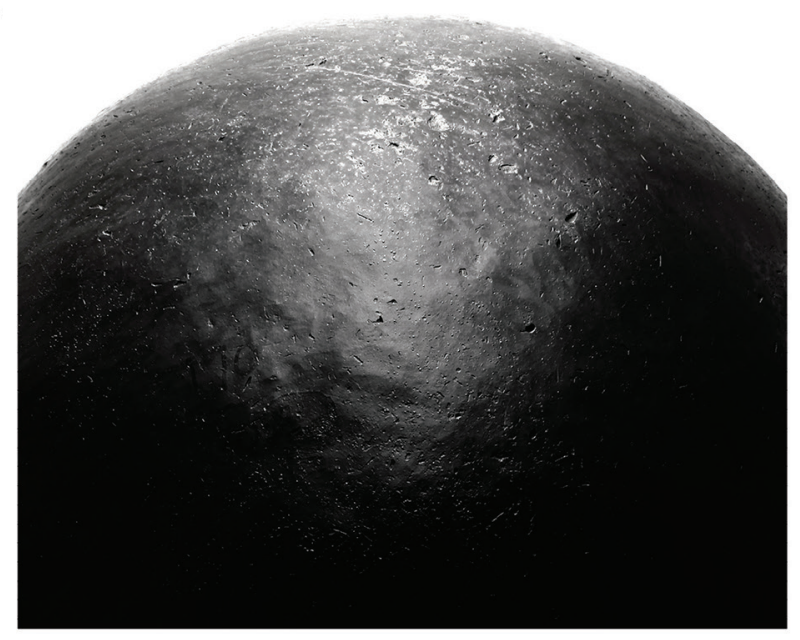

e
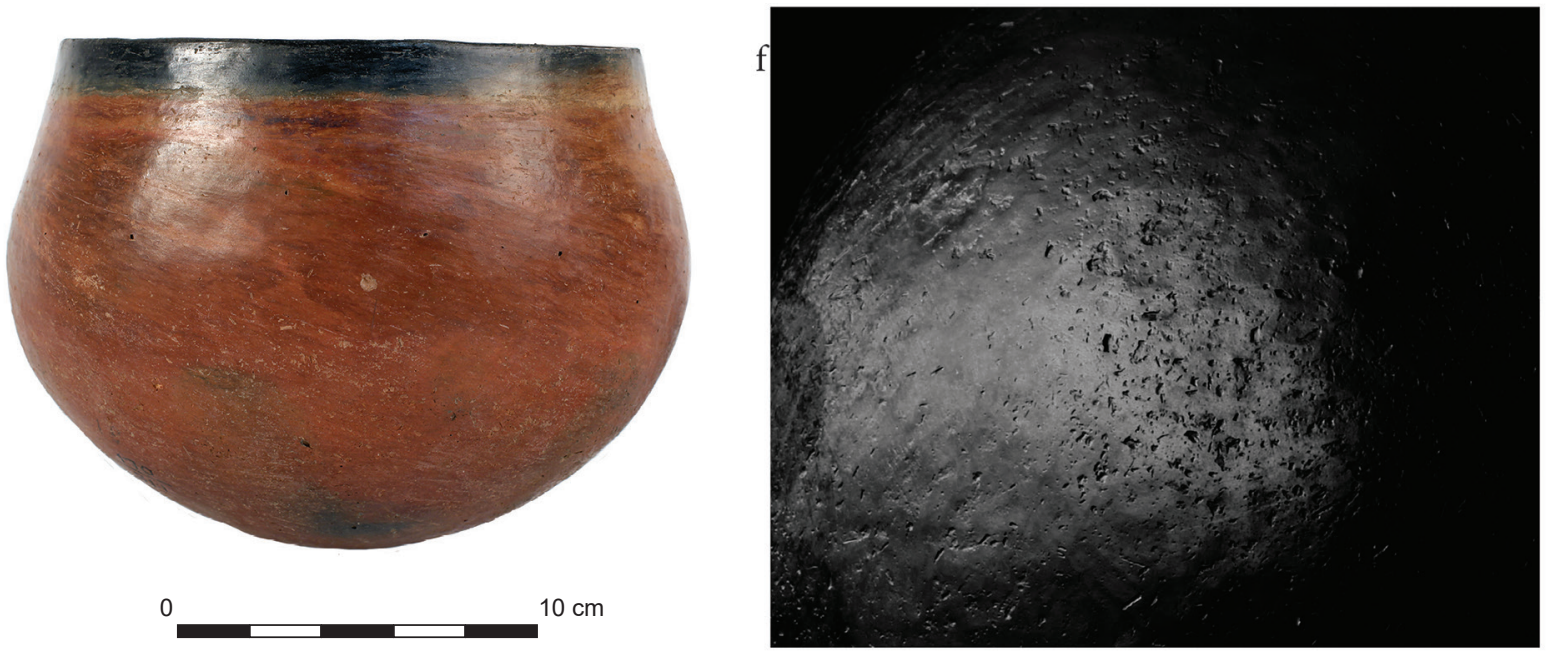

Figure 7. Samples of Pan-Grave style vessels showing possible matting impressions: (a) 332/33:2 photograph (b) 332/33:2 RTI in specular enhancement mode; (c) 170/30:1 photograph (d) 170/30:1 RTI in specular enhancement mode; (e) 170/31:1 photograph (f) 170/31:1 RTI in specular enhancement mode. 
a

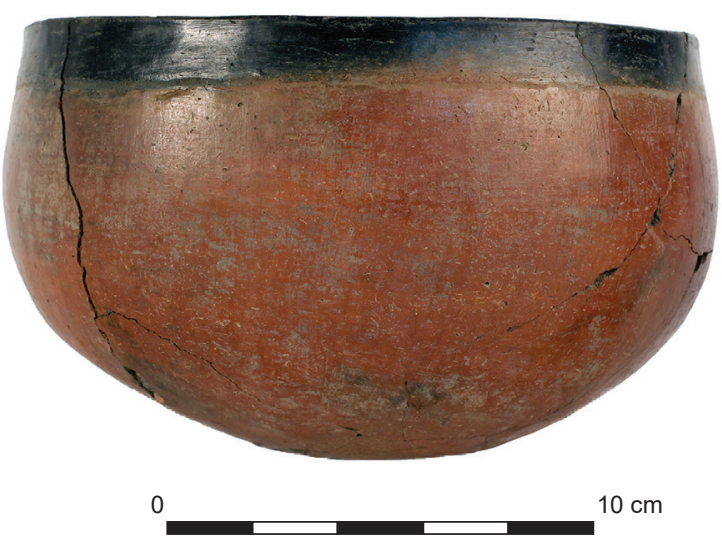

C

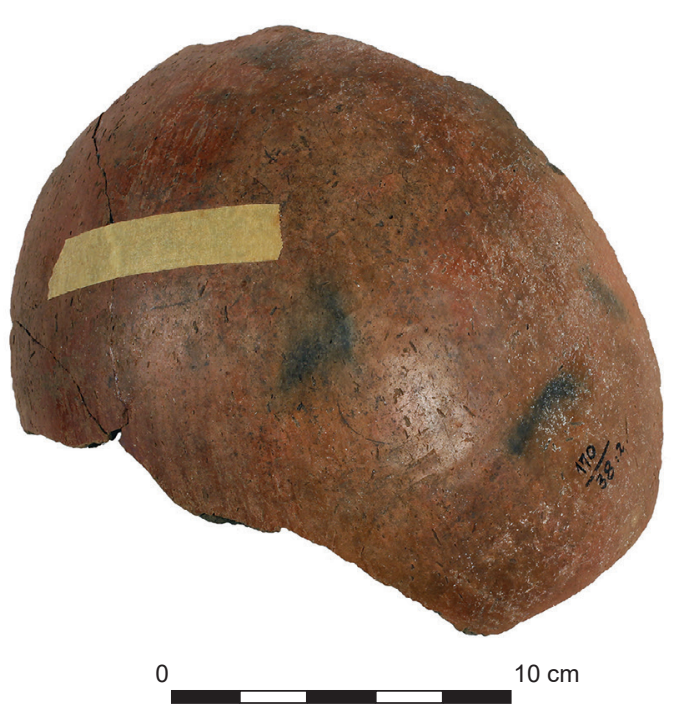

e

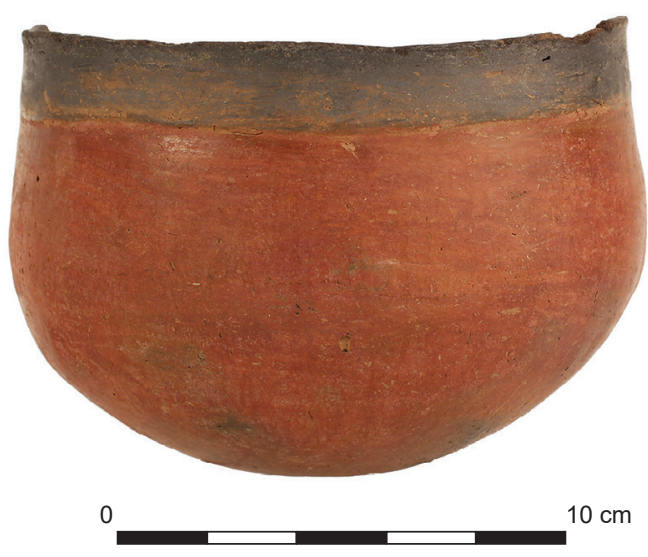

b

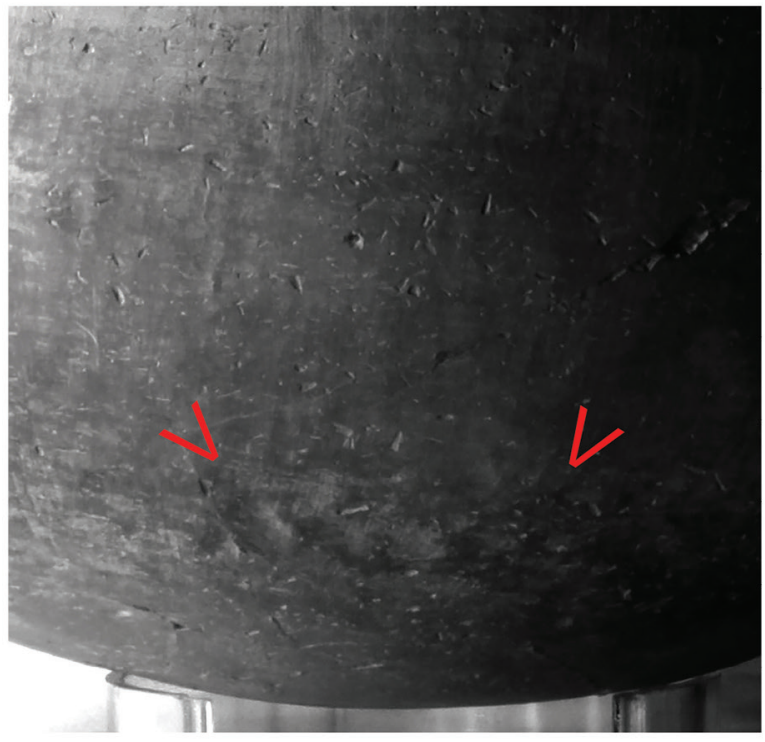

d
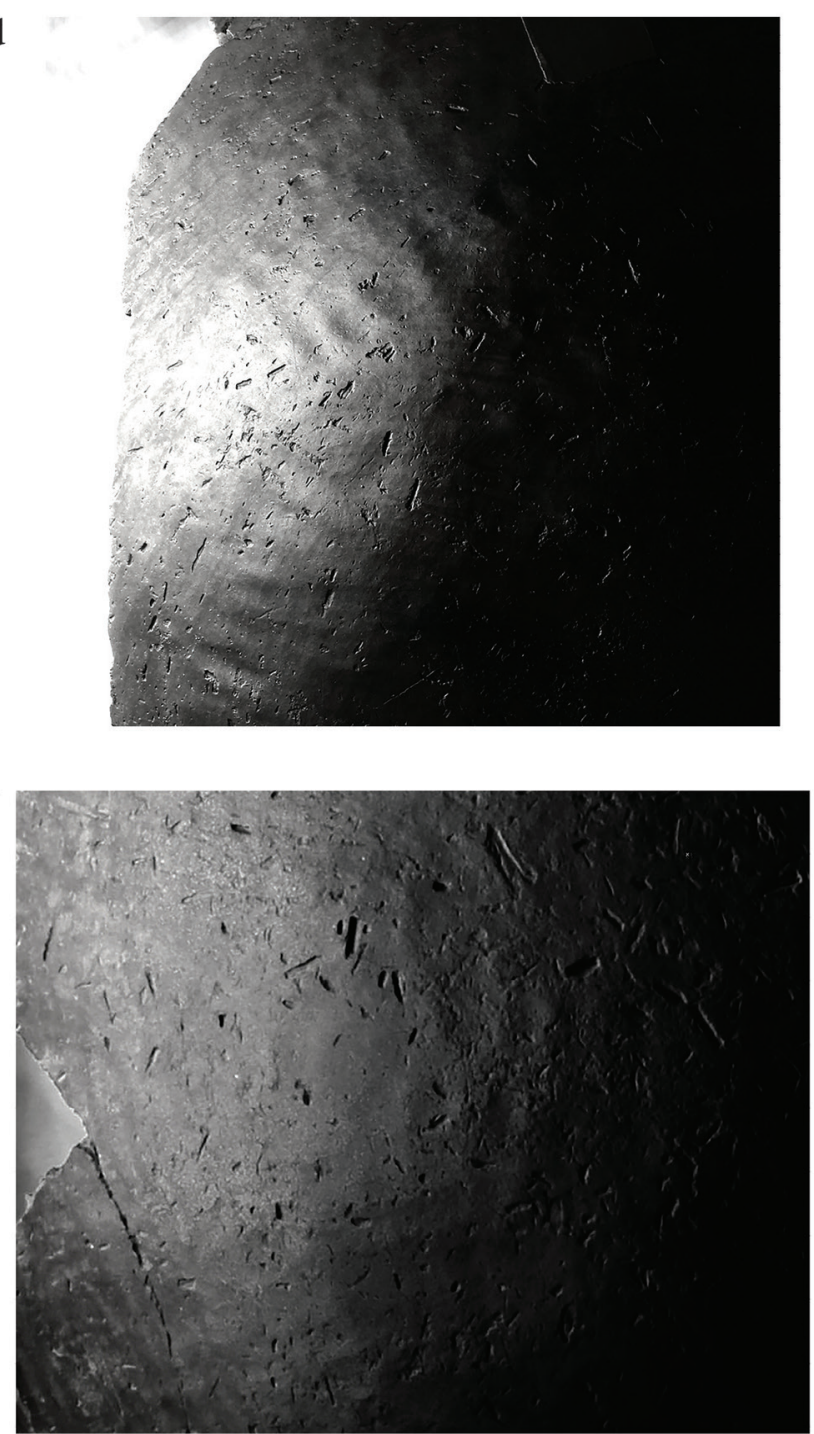

Figure 8. Samples of Pan-Grave style vessels showing possible matting impressions: (a) 170/2:1 photograph (b) 170/2:1 RTI in specular enhancement mode (dimples marked by red arrows; (c) 170/38:2 photograph (d) 170/38:2 RTI in specular enhancement mode; (e) 410/21:2 photograph (f) 410/21:2 RTI in specular enhancement mode. 
(Table 2). In all of these cases, the surfaces of the vessels appeared entirely smooth.

\section{Discussion and conclusions}

Based on the traces observed on the vessel surfaces, the analysed samples could be divided into two technological groups, namely paddle-forming and building on a mat, which will be discussed in detail below. These technological groups correspond very closely to the cemetery groups and, by extension, it is suggested that they correspond also to pottery-making traditions and potentially also to cultural traditions.

\subsection{Paddle forming}

The first technological group displays flattened facets on the vessel exterior, which were observed exclusively on the samples from SJE Site 65 (Figures 5 and 6). This type of facetting is hypothesised as being consistent with the paddleand-anvil process, whereby a vessel is formed by beating the clay into shape using a flat implement (a "paddle") with or without a supporting device on the interior side (an "anvil"). The clay may also be beaten over a mould (Arnold, 1993, pp.17-20; Shepard, 1954, pp.59-60). In order to confirm that these facets are products of the paddling process, RTI was applied to a modern experimental vessel produced by Georgia Kordatzaki (Figure 11). Although the resulting vessel is not Nubian in style, it presented a useful opportunity to observe and document the physical traces left on a vessel's surface by the paddle-forming process. G. Kordatzaki's vessel was built using two processes. Coiling was employed as the primary shaping process to build the body of the vessel. The vessel was subsequently refined by paddling as the secondary shaping process, which involved gently beating the vessel into its final shape from the exterior using a flat wooden tool (the "paddle"). As a final step, the vessel exterior was burnished with a polished stone. The RTI process clearly captured the flattened facets on the exterior of the experimental jug left by the paddling process, and which remained visible even after the burnishing process. These flattened marks were analogous to the marks observed on the vessels from SJE Site 65 , strongly suggesting that they are also traces of the paddle-forming process.

The analysed vessels from SJE Site 65 correspond morphologically with the C-Group ceramic tradition according to current definitions (Säve-Söderbergh, 1989, pp.44-52, pl. 16-19), and it is therefore suggested that these vessels from this site were built using paddling as either a primary or secondary-forming process, possibly in combination with coil- or slab-building. Coil-building was likely to have been practiced by Middle Nubian potters as it was already applied in much earlier times (D'Ercole et al., 2017, pp.560-61). Thus, a two-stage forming process is highly probable. It is worth noting that the facets left by the paddling process remain visible using RTI even after the vessels were burnished, which was also evident on the experimental vessel.
The parallel ripples seen on the exterior of three vessels from Site 65 are likely a result of scraping the vessel with a toothed implement to refine and thin the vessel walls. The same marks were observed on the interior of vessels from the same site, and it is possible that the scraping process would have removed traces of coiling. The ripples observed on exteriors of burnished vessels from Site 65 suggest that the scraping marks were diminished by the burnishing process to a point that they only became visible using RTI. The possibility of combining processes was raised by Nordström, who suggested that the C-Group potters combined coiling and paddling (Nordström, 1972, pp.47-48), which is the same process used for the experimental jug described above.

\subsection{Building on a mat}

The second technological group comprises pottery that displays traces of having been built on a mat-lined surface that leaves distinct impressions on the vessel exterior. The interiors of these vessels are almost invariably smooth and compacted, but not burnished. The mat-impressions on the exterior and the smooth, compacted interior surfaces strongly suggest that the wet clay mass was placed on a mat-lined surface and the pressure used to form the vessel was applied from the interior side. This type of technology appears to be absent from SJE Site 65, but was observed at

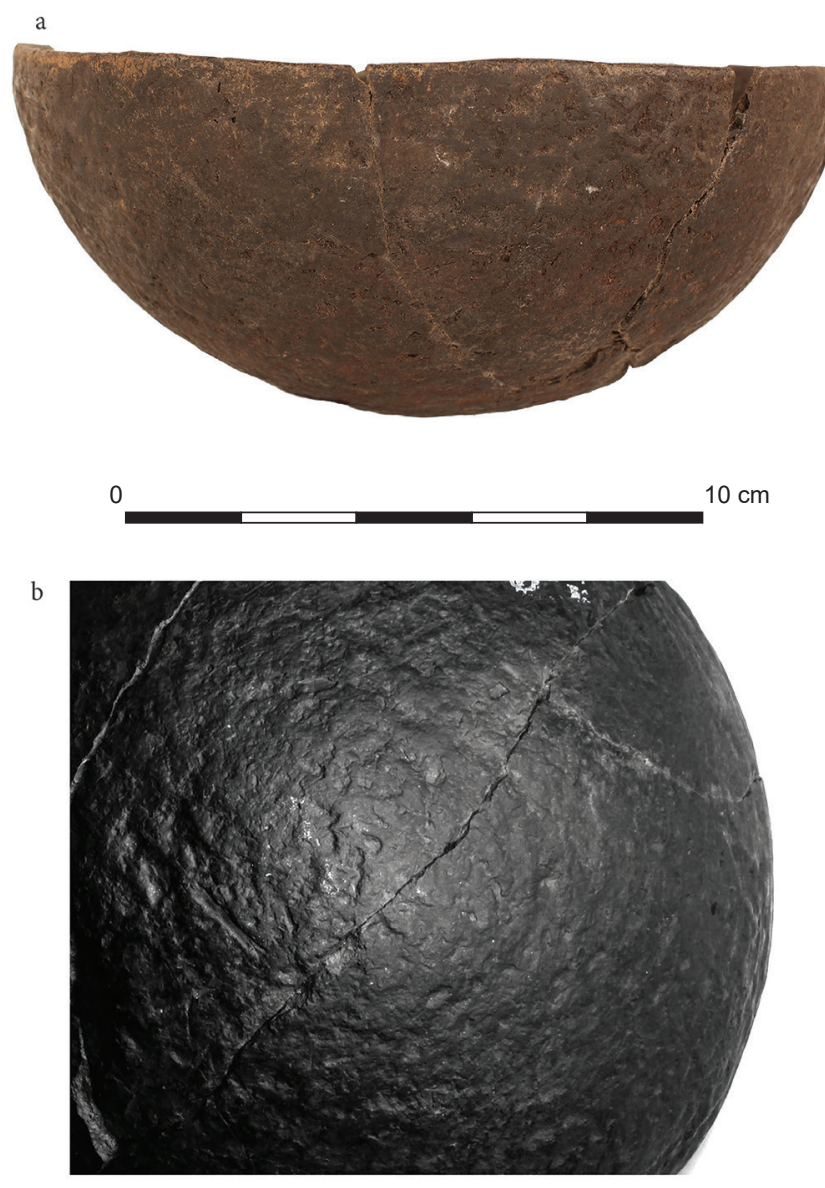

Figure 9. SJE 170/39:3. (a) photograph; (b) RTI image of vessel base showing matting impressions in specular enhancement mode. 

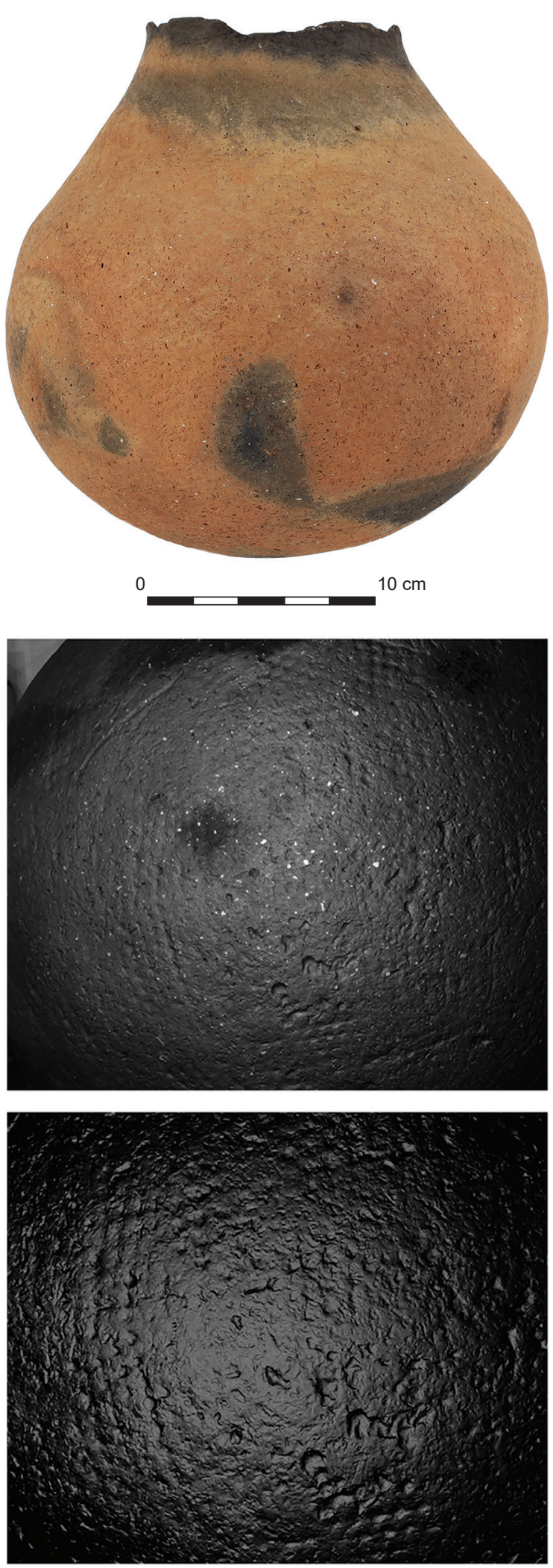

Figure 10. SJE 266/1.B.2 (a) photograph; (b) RTI image in specular enhancement mode (zoom 1.5×); (c) RTI image in specular enhancement Mode (zoom 1.8×).
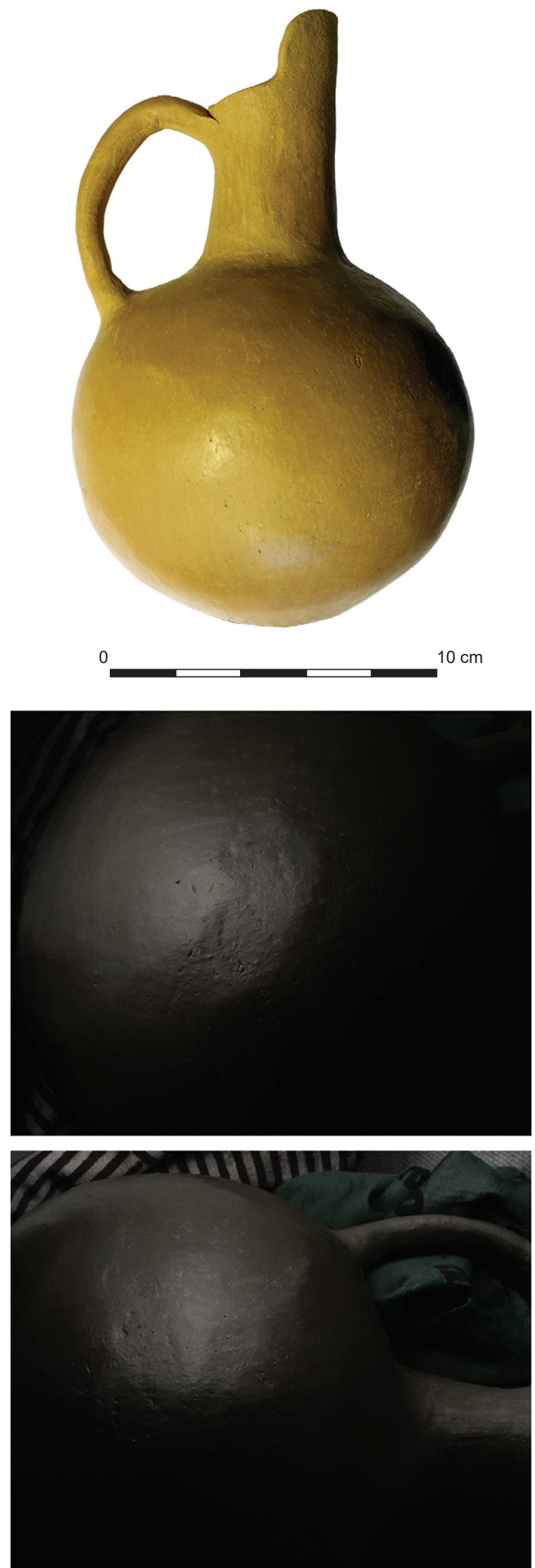

Figure 11. Experimental jug with cutaway neck, made by Dr. G. Kordatzaki. Top: Photograph of the vessel by A. de Souza. Bottom: RTI images of base (left) and shoulder (right) in specular enhancement mode showing flattened areas resulting from the paddling process. 
all of the other sites in this study. The mat-impressions occur as a herringbone weave (Figure 4) or as rows and clusters of small rounded dimples across the vessel surface. Dense coverings of such dimples are easily discerned on sample 170/39:3 (Figure 9) and the large jar 266/1.B.2 (Figure 10), both of which can be attributed to the Kerma ceramic tradition based on their style and available parallels. In these cases, the mat-impressions have been left almost entirely unaltered, and no coating or slip has been applied to the exterior. The frequency with which mat-impressions occur indicates that it was a conscious choice by the potter and hence it can be identified as a surface treatment in its own right.

Clusters of circular impressions towards the vessel base were revealed by RTI on vessels 170/30:1 (Figure 7c-d), 170/31:1 (Figure 7e-f), 170/2:1 (Figure 8a-b), and also on 332/33:2 (Figure 7a-b), all of which can be attributed morphologically to the Pan-Grave tradition according to current definitions. It is suggested that these marks are remnants of mat-impressions based on their resemblance to the marks observed on the Kerma-style vessels 170/39:3 and 266/1.B.2. Both of those vessels are uncoated and unburnished, but on the Pan-Grave style examples, the mat-impressions have been mostly diminished by a red slip coating and intensive burnishing. The dimples were faintly evident to the touch, but became easily visible through RTI.

It is therefore suggested that the vessels in this second technological group can be further divided into two subgroups, one in which the matting impressions were deliberately left as a surface treatment in their own right, and one in which the marks were diminished through subsequent surface treatment processes, e.g., coating, burnishing. The former subgroup correlates well with the pottery assigned to the Kerma ceramic tradition, and the latter with that attributed to the Pan-Grave ceramic tradition.

\subsection{Chaînes opératoires and cultural heritage}

Percussive processes such as the paddle-and-anvil method were likely known to ancient Nubian potters. An ostracon now in Berlin has been interpreted as showing two female Nubian potters making a large jar using this process (Brunner-Traut, 1956, pp.58-9, pl. 50-51; Arnold, 1993, fig. 15A). Arnold tentatively interprets the depiction, which was presumably created by an Egyptian, as an indication that this method of making pottery may have been perceived as an unusual Nubian (i.e., not Egyptian) activity and was hence worthy of documentation, even if only informally (Arnold, 1993, pp.17-20). Whilst there are some clear and problematic assumptions about ethnicity in the interpretation of this ostracon, it nevertheless demonstrates that this vesselforming technique was not unknown in the ancient Nile Valley. The process of beating clay into shape was also postulated by Williams (1983) in his analysis of the Nubian pottery from Adindan (Figure 12), for which he suggests that clay was pounded into shape from the inside on either the flat
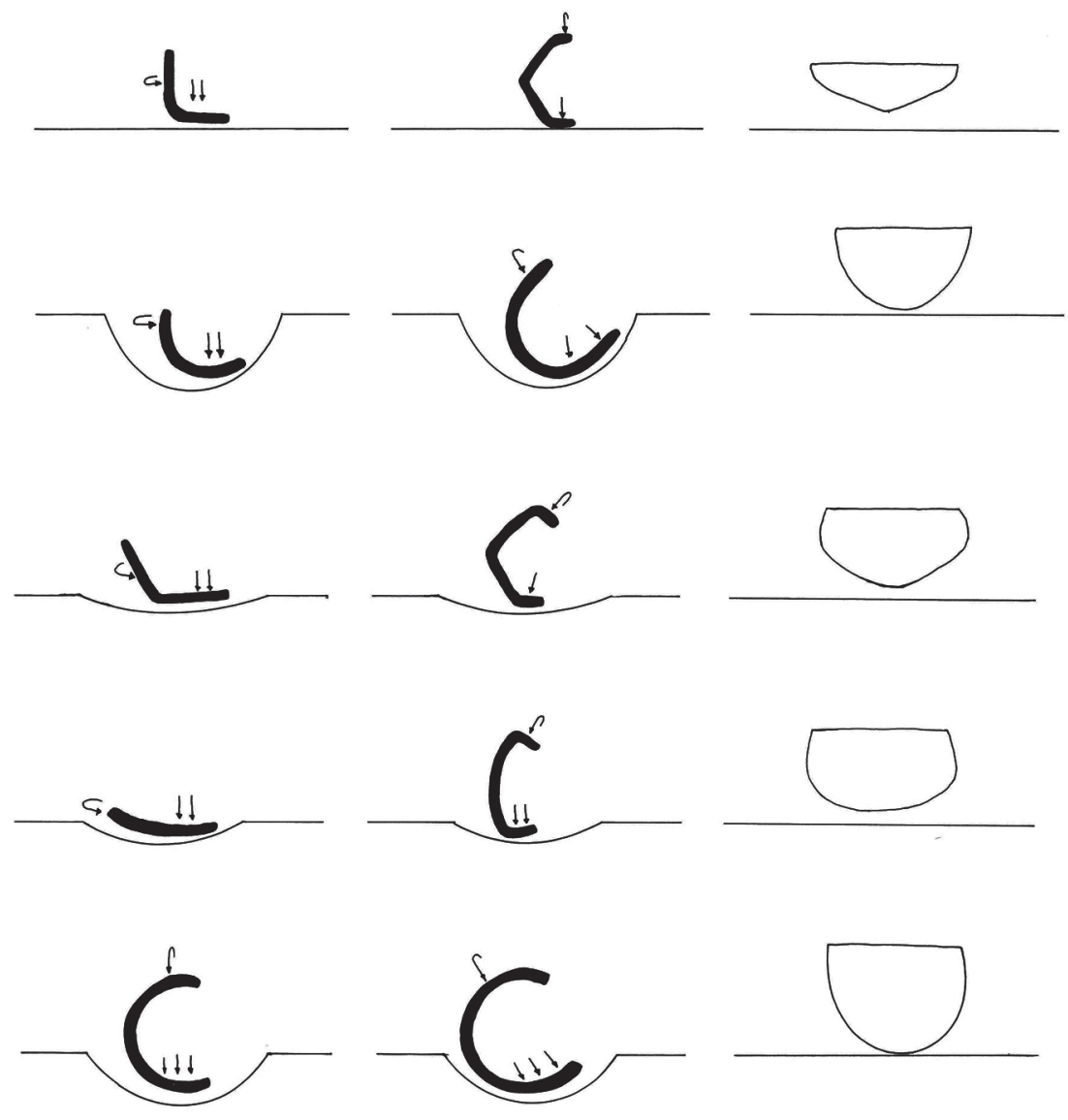

Figure 12. Schematic diagrams showing the process of shaping a pot by beating the clay from the inside into a depression on the ground. (After Williams, 1983, figs. 4-6). 


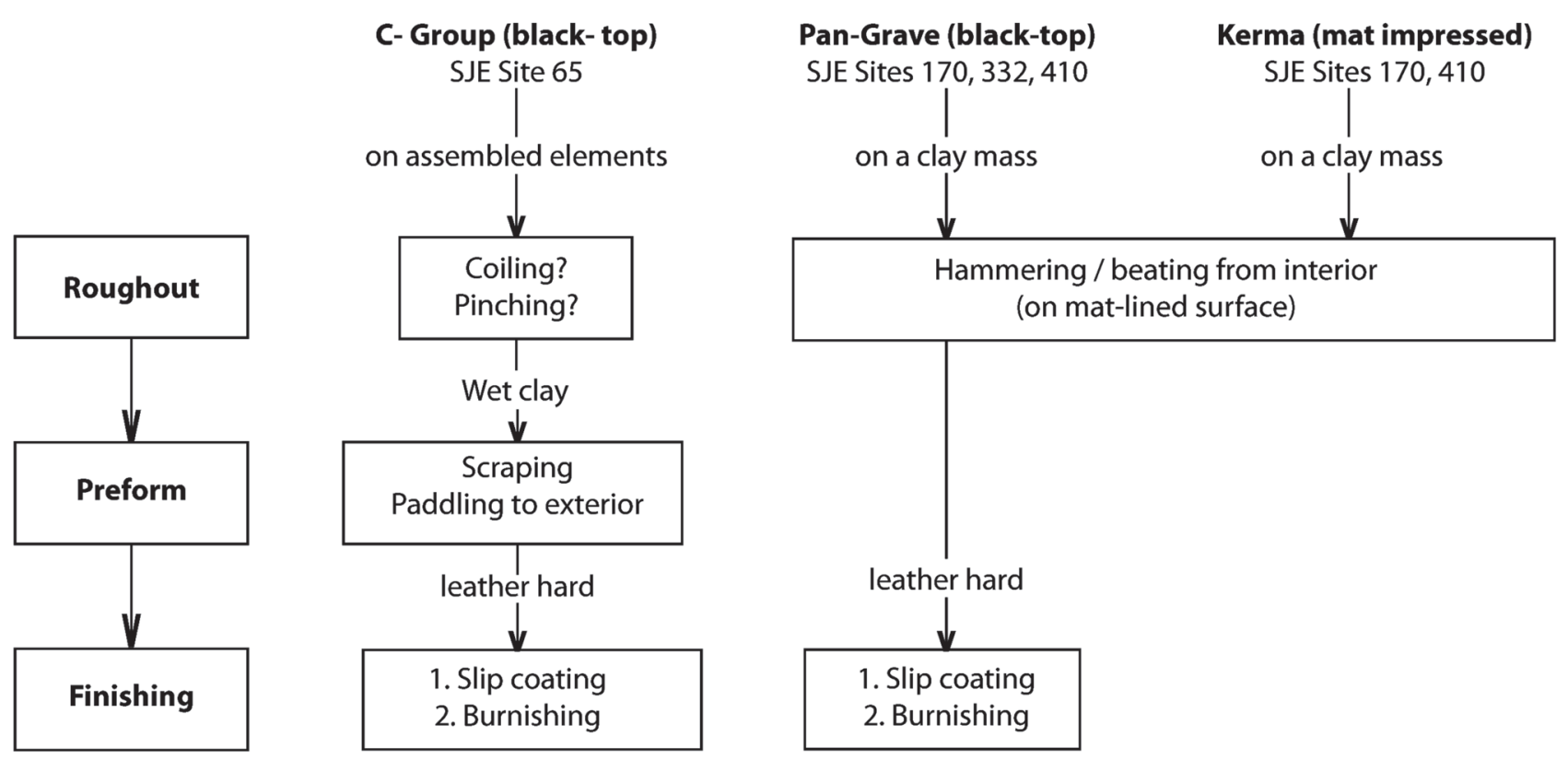

Figure 13. Châine opératoire flow-chart showing the main technological steps for each of the forming techniques identified in the analysis.

ground or in a shallow depression, which may or may not be lined with a mat (Williams, 1983, pp.29-36, figs. 4-6). The same process of building pottery on a mat-lined surface was observed by Reisner at modern Kerma (Reisner, 1966), where he also recorded mats with a closely-spaced rounded weave pattern from ancient Kerma burials (Reisner, 1923, pl. 69.1).

Despite the small sample size in this analysis, the technological differences observed between the samples from each of the sites point towards different material traditions that might, in turn, correspond with different cultural traditions. At least three different chaînes opératoires could be identified based on the forming technologies, which are illustrated in Figure 13. The process is broken down into three manufacturing stages as defined by Roux (2016, pp.5-6), namely roughout, preform, and finishing.

The samples from SJE Site 65, attributed to the C-Group tradition and characterised by the use of the paddling technique, utilise all three of these stages. The roughout stage involves the initial forming of the vessel, most likely using coiling and/or pinching. During the preform stage, the rough form was refined by scraping to thin the walls, and then by paddling of the exterior surface. Both of those processes were done whilst the clay was still wet. When the vessel was leather hard, the finishing processes of coating and burnishing were executed in that order.

Vessels attributed to the Pan-Grave ceramic tradition seem to have followed only a two-stage process. The RTI results support the roughout being made by pressing or beating the wet clay mass into shape from the interior on a mat-lined surface. When the vessel was leather hard, it was finished by coating and burnishing, in that order. The preform stage seems to have been omitted.

Mat-impressed vessels attributed to the Kerma ceramic tradition were apparently subjected to only one stage in the vessel-forming process, namely the roughout stage. The RTI results strongly suggest that the wet clay mass was beaten into shape from the interior on a mat-lined surface. The vessels do not appear to have been further processed in any way, and in all cases, they are uncoated and unburnished.

It therefore appears that the vessels attributed to the C-Group ceramic tradition are technologically distinct from those attributed to Pan-Grave and Kerma traditions, while the latter two appear to have certain features in common. The most fundamental difference is based on the methods by which the wet clay was shaped into the vessel. While the primary shaping processes employed in the C-Group tradition remain unclear, the RTI analysis strongly suggests that paddle forming was used at least as a secondary process. By contrast, the mat-impressed exteriors of pottery attributed to the Pan-Grave and Kerma traditions indicate that the clay was shaped by applying pressure from the interior. The mat-impressed wares attributed to the Kerma tradition are distinct from others in the analysis in that they are not coated or burnished and their uneven surfaces have not been treated by any preforming or finishing processes. Nevertheless, the traces left by forming the vessels on a mat are analogous to the marks observed on vessels from the Pan-Grave tradition, but are entirely absent from the C-Group vessels in this analysis. It is possible that chronological differences may be a factor (see chapter 3), and of course a sample of this size should not be taken as being wholly representative, but the consistency of the results suggests the possibility of fundamentally different technological traditions.

This RTI analysis has provided evidence that the PanGrave and Kerma pottery traditions are technologically more closely related to one another than they are to the C-Group tradition. That being said, caution must be exercised when attempting to link this to "cultural" relatedness as our 
understanding of ancient Nubian groups is in a state of flux. The in-depth study of material technologies, in this case by using RTI, has revealed distinct differences between assemblages, but also showed common features that connect groups that were hitherto treated as separate cultural units. This observation lends weight to the push for an overhaul of the existing culture-historical framework for ancient Nubia, and encourages more detailed analyses of material technologies on the full range of available evidence, of which ceramics is just one aspect.

\section{Acknowledgements}

This research was conducted as part of the first author's InBetween project, which has received funding from the European Union's Horizon 2020 research and innovation programme under the Marie Skłodowska-Curie grant agreement no. 796050. Thank you to the curatorial staff of the Museum Gustavianum, Uppsala University for their permission to work with and publish these objects. Thanks also go to Georgia Kordatzaki (experimental archaeologist \& ceramic petrographer) for permission to use her experimental jug as part of this analysis (facebook. com/JasperHandmadeCeramics) and to Adam Grubner for his photographic assistance. The application of RTI would not have been possible without the materials provided by Cultural Heritage Imaging (http://culturalheritageimaging. org).

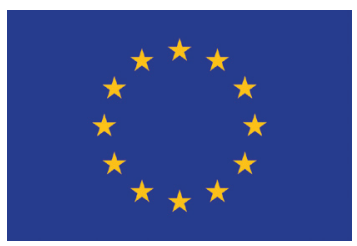

\section{References}

ARNOLD, D., 1993. Techniques and Traditions of Manufacture in the Pottery of Ancient Egypt. In: D. Arnold and J. Bourriau, eds. An Introduction to Ancient Egyptian Pottery. Mainz am Rhein: Philipp von Zabern, pp. 9-137.

BIETAK, M., 1966. Ausgrabungen in Sayala-Nubien 1961-1965. Denkmäler der C-Gruppe und der Pan-Gräber-Kultur, Vienna: Austrian Academy of Sciences.

BIETAK, M., 1968. Studien zur Chronologie der nubischen C-Gruppe. Ein Beitrag zur Frühgeschichte Unternubiens zwischen 2200 und 1550 vor. Chr. Vienna: Austrian Academy of Sciences.

BOURDIEU, P., 1977. Outline of a Theory of Practice. Trans. R. Nice. Cambridge: Cambridge University Press.

BRAND, M., 2018. Early Middle Kingdom Imitation Wares at Wadi elHudi. Cahiers de la céramique Égyptienne, 11, 29-46.

BRUNNER-TRAUT, E., 1956. Die altägyptischen Scherbenbilder (Bildostraka) der deutschen Museen und Sammlungen. Wiesbaden: Franz Steiner.

BUDKA, B., 2017. Pottery from SAV1 North. In: J. Budka, ed. Across Borders I. The New Kingdom Town of Sai Island, Sector SAV1 North. Vienna: Austrian Academy of Sciences, pp. 119-156.

CULTURAL HERITAGE IMAGING (CHI), 2013. Guide to RTIViewer v 1.1. [online]. Cultural Heritage Imaging (CHI). [25/04/2020]. Available from: http://culturalheritageimaging.org/What_We_Offer/Downloads/ rtiviewer/RTIViewer_Guide_v1_1.pdf

D'ERCOLE, G., GARCEA, E.A.A., ERAMO, G., and MUNTONI, I., 2017. Variability and continuity of ceramic manufacturing of prehistoric pottery from Upper Nubia, Sudan: An ethnographic comparison. Journal of Archaeological Science: Reports, 16, 553-563.

DE SOUZA, A.M., 2019. New Horizons: The Pan-Grave ceramic tradition in context. London: Golden House.

DE SOUZA, A.M., 2020. Pots, Gold, and Viceroys: Shifting dynamics of Egyptian-Nubian relations at the transition to the New Kingdom, from the viewpoint of Middle Nubian pottery at Tell Edfu, Ägypten \& Levante, 30, 313-343.

DE SOUZA, A.M., OWNBY, M.F., in preparation. Petrographic Analysis of Middle Nubian Pottery from the Second Nile Cataract, Sudan.

EARL, G., MARTINEZ, K., MALZBENDER, T., 2010. Archaeological applications of polynomial texture mapping: analysis, conservation and representation. Journal of Archaeological Science, 37(8), 2040-2050. DOI: $10.1016 /$ j.jas.2010.03.009

EARL, G., BASFORD, P., BISCHOFF, A., BOWMAN, A., CROWTHER, C., DAHL, J., HODGSON, M., ISAKSEN, L., KOTOULA, E., MARTINEZ, K., PAGI, H., PIQUETTE, K.E., 2011. Reflectance transformation imaging systems for ancient documentary artefacts. In: J. P. Bowen, S. Dunn, and K. Ng, eds. EVA London 2011: Electronic Visualisation and the Arts. Science Open, pp. 147-154. DOI: 10.14236/ ewic/EVA2011.27

EDWARD, D., 2004.The Nubian Past. London: Routledge.

GOSSELAIN, O.P. 2012. Technology. In: T. Insoll, ed. Oxford Handbook of the Archaeology of Ritual and Religion. Oxford: Oxford University Press, pp. 243-260.

GOSSELAIN, O.P., 2018. Pottery chaînes opératoires as Historical Documents. In: Oxford Research Encyclopedia of African History. DOI: 10.1093/acrefore/9780190277734.013.208

HISTORIC ENGLAND, 2018. Multi-light Imaging for Cultural Heritage. [online]. [25/04/2020]. Available from: https://historicengland.org.uk/ images-books/publications/multi-light-imaging-heritage-applications/

MALZBENDER, T., GELB, D., WOLTERS, H., ZUCKERMAN, B., 2000. Enhancement of Shape Perception by Surface Reflectance Transformation, Hewlett-Packard Technical Report HPL-2000-38. [online]. [25/04/2020]. Available from: http://www.academia.edu/download/49215561/ Enhancement_of_Shape_Perception_by_Surfa20160929-18736-71vuyz. pdf

MALZBENDER, T., GELB, D., WOLTERS, H., 2001. Polynomial texture maps. In: Proceedings of the $28^{\text {th }}$ annual conference on Computer graphics and interactive techniques (SIGGRAPH '01), pp. 519-528. DOI: $10.1145 / 383259.383320$

MUdGE, M., MALZBENDER, T., SCHROER, C., LUM, M., 2006. New Reflection Transformation Imaging Methods for Rock Art and MultipleViewpoint Display. In: M. Ioannides, D. Arnold, F. Niccolucci, K. Mania, eds. VAST: International Symposium on Virtual Reality, Archaeology and Intelligent Cultural Heritage. The Eurographics Association, pp. 195202. DOI:10.2312/VAST/VAST06/195-202

NORDSTRÖM, H-Å., 1972. Neolithic and A-Group Sites. Uppsala: Scandinavian University Books.

PAlMA, G., CORSINI, M., CIGNONI, P., SCOPIGNO, R., MUdGE, M., 2010. Dynamic shading enhancement for reflectance transformation imaging. Journal on Computing and Cultural Heritage, 3(2), Article 6. DOI: $10.1145 / 1841317.1841321$

PIQUETTE, K.E., 2013. "It Is Written"?: Making, remaking and unmaking early "writing" in the lower Nile Valley. In: K.E. Piquette and R.D. Whitehouse, eds. Writing as Material Practice: Substance, surface and medium. London: Ubiquity Press, pp. 213-238. DOI: 10.5334/bai.k

RAUE, D. 2019. Cultural Diversity of Nubia in the Later $3^{\text {rd }}-$ Mid2 $^{\text {nd }}$ Millennium BC. In: D. Raue, ed. Handbook of Ancient Nubia. Berlin: De Gruyter, pp. 293-334.

REISNER, G.A., 1923. Excavations at Kerma. Cambridge: Harvard University Press.

REISNER, G.A., 1966. Black-Topped Pottery. Journal of the American Research Centre in Egypt, 5, 7-10.

ROSE, P., 2012. Early $18^{\text {th }}$ Dynasty Nubian Pottery from the Site of Sesebi, Sudan. In: I. Forstner-Müller and P. Rose, eds. Nubian Pottery from 
Egyptian Cultural Contexts of the Middle and Early New Kingdom. Proceedings of a Workshop held at the Austrian Archaeological Institute at Cairo. 1-12 December 2010. Vienna: Austrian Archaeological Institute, pp. 13-29.

ROUX, V., 2016. Ceramic Manufacture: The chaîne opératoire Approach. In: A. Hunt, ed. The Oxford Handbook of Archaeological Ceramic Analysis. Oxford: Oxford University Press, pp. 101-113.

RUFFIEUX, P., 2012. The Pottery of Dukki Gel (2011-2012 Campaign). In: M. Honegger et al., eds. Kerma 2011-2012, Soudan. Documents de la mission archéologique Suisse au Soudan, 4, pp. 37-40.

SÄVE-SÖDERBERGH, T., 1970. Introduction. In: P. Hellström (with H. Langballe): The Rock Drawings. The Scandinavian Joint Expedition to Sudanese Nubia, 1. Copenhagen: Scandinavian University Books, pp. 13-24.

SÄVE-SÖDERBERGH, T., 1989. Middle Nubian Sites. Partille: Paul Åström Editions.

SCHROER, C., 2014. Geeky details about the "Normals Visualization" available in the new viewer. [online] [viewed 26/04/2020]. Available from: http://forums.culturalheritageimaging.org/topic/302-geeky-detailsabout-the-normals-visualization-available-in-the-new-viewer

SHEPARD, A.O. 1985. Ceramics for the Archaeologist. $5^{\text {th }}$ ed. Washington D.C.: Carnegie Institution of Washington.

TROGNITZ, M., 2016. Reflectance Transformation Imaging (RTI). [online] In: M. Heinrich, F. Schäfer, and M. Trognitz, eds. IT-Empfehlungen für den nachhaltigen Umgang mit digitalen Daten in den Altertumswissenschaften . [viewed 18/04/2020]. DOI: 10.13149/000.111000-a

WEB CHI 2020a. Reflectance Transformation Imaging (RTI). [online]. Cultural Heritage Imaging (CHI). [19/04/2020]. Available from: http:// culturalheritageimaging.org/Technologies/RTI/index.html

WEB CHI 2020b. RTI Capture. [online]. Cultural Heritage Imaging (CHI). [25/04/2020]. Available from:

http://culturalheritageimaging.org/What_We_Offer/Downloads/Capture/ index.html

WEB CHI 2020c. Process: RTIBuilder Download. [online]. Cultural Heritage Imaging (CHI). [25/04/2020]. Available from: http:// culturalheritageimaging.org/What_We_Offer/Downloads/Process/index. html

WEB CHI 2020d. View: RTIViewer Download Version 1.1. [online]. Cultural Heritage Imaging (CHI). [25/04/2020]. Available from: http:// culturalheritageimaging.org/What_We_Offer/Downloads/View/index. html

WEB CNR-ISTI 2020. Palma, G. WebRTIViewer. [online]. Visual Computing Laboratory at CNR-ISTI in Pisa. [18/04/2020]. Available from: http://vcg.isti.cnr.it/rti/webviewer.php

WILLIAMS, B.B., 1983. Excavations Between Abu Simbel and the Sudan Frontier. C-Group, Pan-Grave, and Kerma remains at Adindan Cemeteries $T, K, U$, and $J$. Chicago: Oriental Institute of the University of Chicago. 
